Review

\title{
The Relationship of Docosahexaenoic Acid (DHA) with Learning and Behavior in Healthy Children: A Review
}

\author{
Connye N. Kuratko ${ }^{1, *}$, Erin Cernkovich Barrett ${ }^{1}$, Edward B. Nelson ${ }^{1}$ and \\ Norman Salem, Jr. ${ }^{1}$
}

DSM Nutritional Products, 6480 Dobbin Road Columbia, MD 21045, USA;

E-Mails: erin.barrett@dsm.com (E.C.B.); ed.nelson@dsm.com (E.B.N.); norman.salem@dsm.com (N.S.)

* Author to whom correspondence should be addressed; E-Mail: connye.kuratko@dsm.com; Tel.: +1-443-542-2552; Fax: +1-410-740-2985.

Received: 2 May 2013; in revised form: 4 June 2013 / Accepted: 8 June 2013 /

Published: 19 July 2013

\begin{abstract}
Childhood is a period of brain growth and maturation. The long chain omega-3 fatty acid, docosahexaenoic acid (DHA), is a major lipid in the brain recognized as essential for normal brain function. In animals, low brain DHA results in impaired learning and behavior. In infants, DHA is important for optimal visual and cognitive development. The usual intake of DHA among toddlers and children is low and some studies show improvements in cognition and behavior as the result of supplementation with polyunsaturated fatty acids including DHA. The purpose of this review was to identify and evaluate current knowledge regarding the relationship of DHA with measures of learning and behavior in healthy school-age children. A systematic search of the literature identified 15 relevant publications for review. The search found studies which were diverse in purpose and design and without consistent conclusions regarding the treatment effect of DHA intake or biomarker status on specific cognitive tests. However, studies of brain activity reported benefits of DHA supplementation and over half of the studies reported a favorable role for DHA or long chain omega-3 fatty acids in at least one area of cognition or behavior. Studies also suggested an important role for DHA in school performance.
\end{abstract}

Keywords: docosahexaenoic acid; children; learning; behavior; school performance 


\section{Introduction}

The period from birth to 2 years of age is considered the primary growth phase for the human brain when measured in terms of brain weight. However, certain areas of the brain are not fully developed by the age of two, and development as well as growth continues throughout childhood and adolescence [1]. Myelination of brain frontal lobes begins as early as 6 months of age and continues throughout childhood and adolescence with spurts of development identified at 2 years of age, 7-9 years of age, and during mid-adolescence [1]. Tissue content of the long chain, omega-3 fatty acid (n-3 LC-PUFA) docosahexaenoic acid (DHA, 22:6n-3) is important for this development. DHA-rich frontal lobes are thought to be responsible for executive and higher-order cognitive activities such as planning, problem solving, and focused attention [2]. Investigators report an association of these prefrontal cortex structures with the limbic system, where the development of high-level cognitive function also correspond to a child's social, emotional and behavioral development $[3,4]$.

Many components of the diet are known to affect cognition and influence learning. DHA in particular is recognized as essential for normal brain function. DHA is the principal omega-3 fatty acid in brain gray matter representing about $15 \%$ of all fatty acids in the human frontal cortex [5] and is known to affect neurotransmitter pathways, synaptic transmission, and signal transduction. Its multiple double bonds and unique structure allow DHA to impart a disorder to membranes which allows for effective cell signaling [6,7]. Studies in animals and humans show that adequate levels of DHA in neural membranes are important for cortical astrocyte maturation and vascular coupling, and for cortical glucose uptake and metabolism [8-13]. In addition, certain metabolites of DHA are bioactive molecules which protect tissues from oxidative injury and stress [14-17]. In animals, low brain DHA results in changes in behavior and is associated with learning problems and memory deficits [18]. In humans, studies at various life stages indicate that DHA supports normal IQ [19] and preserves visuo-spatial learning and memory [20]. For the brain and retina, therefore, it is clear that adequate DHA composition allows for optimal function [12]. Low blood levels of $n$-3 LC-PUFA, as well as high $n-6$ to $n-3$ ratios are reported in children with certain developmental and behavioral disorders such as attention deficit hyperactivity disorder (ADHD), dyslexia, or dyspraxia. Although inconsistent, various fatty acid supplementation strategies, some of which included DHA, proved to benefit measures of learning and behavior in these children. Some investigators even report clinical signs of fatty acid deficiency in these children which respond to $n$-3 LC-PUFA supplementation [21,22]. Reasons for this low omega-3 status are not fully understood, but could include disorders of fatty acid metabolizing enzymes and pathways which are unique to the disease. However, the explanation could also include a childhood history of inadequate $n-3$ fatty acid intake [23-25]. This brings to question whether poor $n-3$ LC-PUFA status in otherwise healthy children might also impact learning, memory, and behavior. If so, could improvement in n-3 LC-PUFA status, and DHA status in particular, improve learning and performance in healthy children? The current review was conducted to assess current knowledge regarding the relationship of DHA with learning (including such measures as reading and spelling), memory, and behavior in healthy children. 


\section{Experimental Section}

All observational studies evaluating DHA intake or status as well as randomized controlled trials (RCT) evaluating DHA supplementation (with or without the addition of other fatty acids and nutrients) in healthy children, age 4 to 18 years, were considered for review. Eligible outcomes included all measures of cognitive function, learning, and behavior, with special interest in school performance or assessments such as those for reading, spelling, or listening comprehension. For inclusion, the publication had to quantify DHA in the diet or supplement, or include DHA as a biomarker measured in tissue or blood. Analyses had to report neurocognitive outcomes in relation to a concurrent indicator of DHA intake or status. Studies were included if subjects were generally described as healthy, without diagnosis of a neuropsychological condition, and participating in the available mainstream school setting. Studies in children with known deficiencies in nutrients other than DHA were included if no psychological or learning disabilities were apparent. Studies in children diagnosed with a learning disability or with special educational needs were excluded. Many of the authors of the studies included in this review performed multiple analyses due to an interest in several outcomes and various subgroups. While it is true that the more analyses that are done, the more likely that some of them will be statistically significant by chance, the correction for multiple comparisons applied by the study authors was not consistent. In order to provide a comprehensive review of the literature and avoid re-interpretation of the reported outcomes, no studies were excluded due to method of statistical assessment.

Studies which included $\alpha$-linolenic acid (ALA, 18:3n-3) or sources of ALA as the only treatment intervention were excluded. However, studies which used micronutrient or fatty acid mixtures were included if the formulation included DHA. Whenever multiple publications reported unique analyses pertaining to the same subjects, all publications were retained. The database of PubMed was searched in November, 2012 using a predefined algorithm. References from pertinent systematic reviews were screened for potential articles that might have been missed in the search.

Search results were sorted by an investigator at the title/abstract level, eliminating inappropriate articles. Two investigators independently reviewed the full papers of the remaining studies to determine the final accepted list. The search criteria were built on the following PubMed Mesh terms:

(("Fatty Acids, Omega-3" [Mesh] OR "Fish Oils" [Mesh]) OR "Docosahexaenoic Acids" [Mesh]) OR "Eicosapentaenoic Acid" [Mesh]

And

(((((“Learning” [Mesh] OR "Memory” [Mesh]) OR "Reading” [Mesh]) OR “Students" [Mesh]) OR "Schools" [Mesh]) OR “Education” [Mesh]) OR "Educational Status" [Mesh]

And

Filters activated: English, Preschool Child: 2-5 years, Child: 6-12 years, Adolescent: 13-18 years.

Search terms to select the populations of interest included: All infant birth-23 months; Preschool Child 2-5 years, Child 6-12 years.

Exclusion criteria included subject populations of children diagnosed with or a history of ADHD, dyslexia, autism, dyspraxia, or learning disabilities requiring special education, or medication use for any of these conditions. Other exclusions included fish-only interventions without calculation or confirmation of the fatty acids provided; analyses reporting only fish-related outcomes, with no report 
of fatty acid contribution; reviews or mechanistic papers; outcomes from in vitro or animal models; and follow-up studies of prenatal or infant interventions failing to report intake or biomarker data corresponding with outcome assessments in the older child.

\section{Results}

\subsection{Search Results}

Using the above criteria, the PubMed search resulted in 38 citations. Level 1 Screening, based on the abstract excluded 24 articles. Full papers were retrieved for the 14 remaining studies, two of which were excluded. Three additional studies were located from reviewing the references in the retrieved papers. Fifteen articles conducted in healthy children ages 4-14 years met the full criteria for inclusion in this review. Tables 1 and 2 include a list of the final accepted studies with reported outcomes. Table 3 is a summary of DHA biomarker data reported by study.

Three studies were observational in design [26-28]. Bakker et al. [26] and Boucher et al. [27] provided a prospective analysis of cohorts identified in infancy and followed through age 7 and through 10-13 years, respectively. The cross-sectional study by Kirby et al. [28] reported correlations between cheek cell fatty acids, including DHA, with relevant cognitive and behavioral outcomes.

The remaining 12 studies were randomized, controlled trials of varied purpose and design. The sources of DHA administered as the intervention included triglycerides from fish oil and algal oil. The oils were given as supplements in capsules or chewable form, or were incorporated into fortified foods. Experimental designs often included additional nutrients, such as vitamins, minerals, or other fatty acids. In most of the studies, the placebo consisted of corn, soy, or olive oil, or a combination of those vegetable oils. Daily doses of DHA ranged from 88 to $1200 \mathrm{mg}$ per day. 
Table 1. Observational studies reporting docosahexaenoic acid (DHA)-related outcomes of cognition and behavior in children.

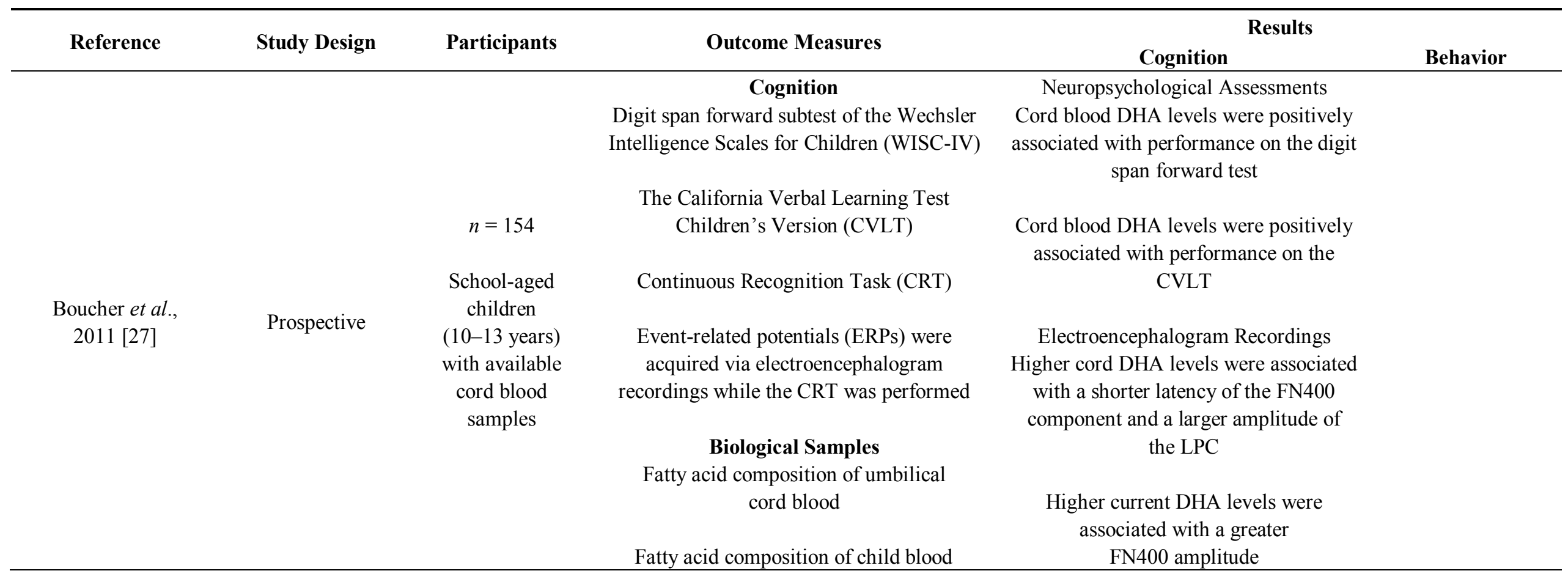


Table 1. Cont.

\section{Cognition}

Kaufman Brief Intelligence Test (KBIT-2)

Working Memory Test Battery for Children (WMTB-C)

Wechsler Individual Achievement Test (WIAT-II)

Test of Everyday Attention for Children

$$
\text { (TEA-Ch) }
$$

$$
n=411
$$

Kirby et al., 2010 [28]

\section{School-aged \\ children \\ (8-10 years)}

Matching Familiar Figures Task (MFFT)

\section{Behavior}

Swanson, Nolan, and Pelham (SNAP-IV; parents/guardians and teachers)

Strengths and Difficulties Questionnaire (SDQ; parents/guardians and teachers)

Developmental Coordination Disorder Questionnaire (DCDQ; parents/guardians)
Cheek cell DHA levels were negatively associated with teacher rated hyperactivity and total difficulties (SDQ)

Biological Samples

Cheek cell samples for measurement of fatty acid composition 
Table 1. Cont.

\begin{tabular}{|c|c|c|c|c|}
\hline $\begin{array}{c}\text { Bakker et al., } \\
2003 \text { [26] }\end{array}$ & Prospective & $\begin{array}{l}\quad n=306 \\
\text { School-aged } \\
\text { children } \\
\text { (7 years of age) } \\
\text { with available } \\
\text { cord blood } \\
\text { samples }\end{array}$ & $\begin{array}{l}\text { Cognition } \\
\text { Kaufman Assessment Battery for Children } \\
\text { (K-ABC) } \\
\text { Biological Samples } \\
\text { Fatty acid composition of umbilical } \\
\text { cord blood } \\
\text { Fatty acid composition of child blood at age } 7\end{array}$ & $\begin{array}{c}\text { There was no association between cord } \\
\text { blood DHA levels and cognitive } \\
\text { performance (K-ABC) } \\
\text { There was no association between } \\
\text { plasma DHA at age } 7 \text { and cognitive } \\
\text { performance }(\mathrm{K}-\mathrm{ABC})\end{array}$ \\
\hline
\end{tabular}

Abbreviations: California Verbal Learning Test (CVLT), Continuous Recognition Task (CRT), Developmental Coordination Disorder Questionnaire (DCDQ), Event-Related Potentials (ERP), Kaufman Assessment Battery for Children (K-ABC), Kaufman Brief Intelligence Test (KBIT), Matching Familiar Figures Task (MFFT), Test of Everyday Attention for Children (TEA-Ch), Strengths Difficulties Questionnaire (SDQ), Swanson, Nolan, and Pelham (SNAP), Wechsler Individual Achievement Test (WIAT), Wechsler Intelligence Scales for Children (WISC), Working Memory Test Battery for Children (WMTB-C). 
Table 2. Clinical trials of DHA supplementation on outcomes of cognition and behavior in children.

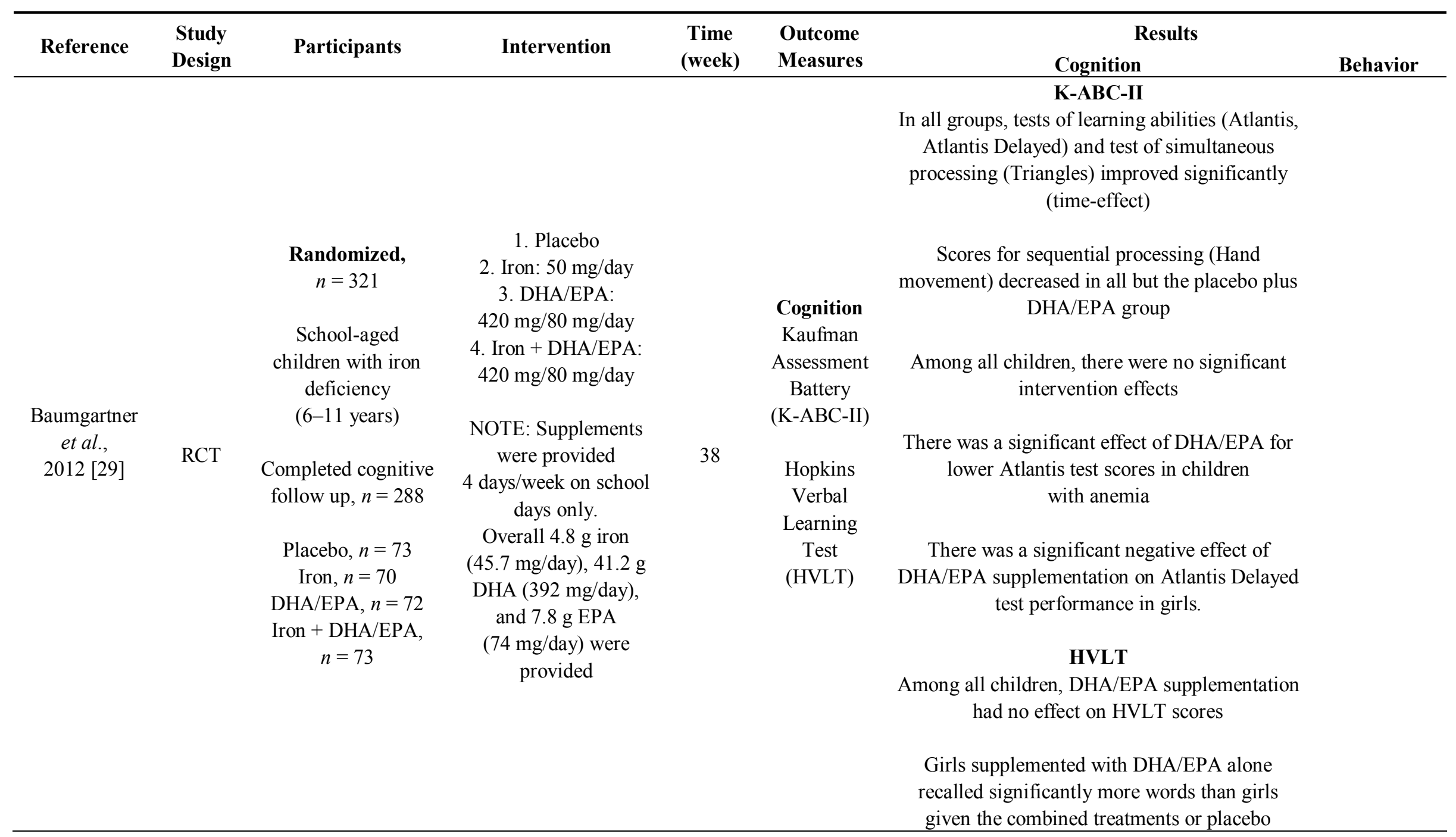


Table 2. Cont.

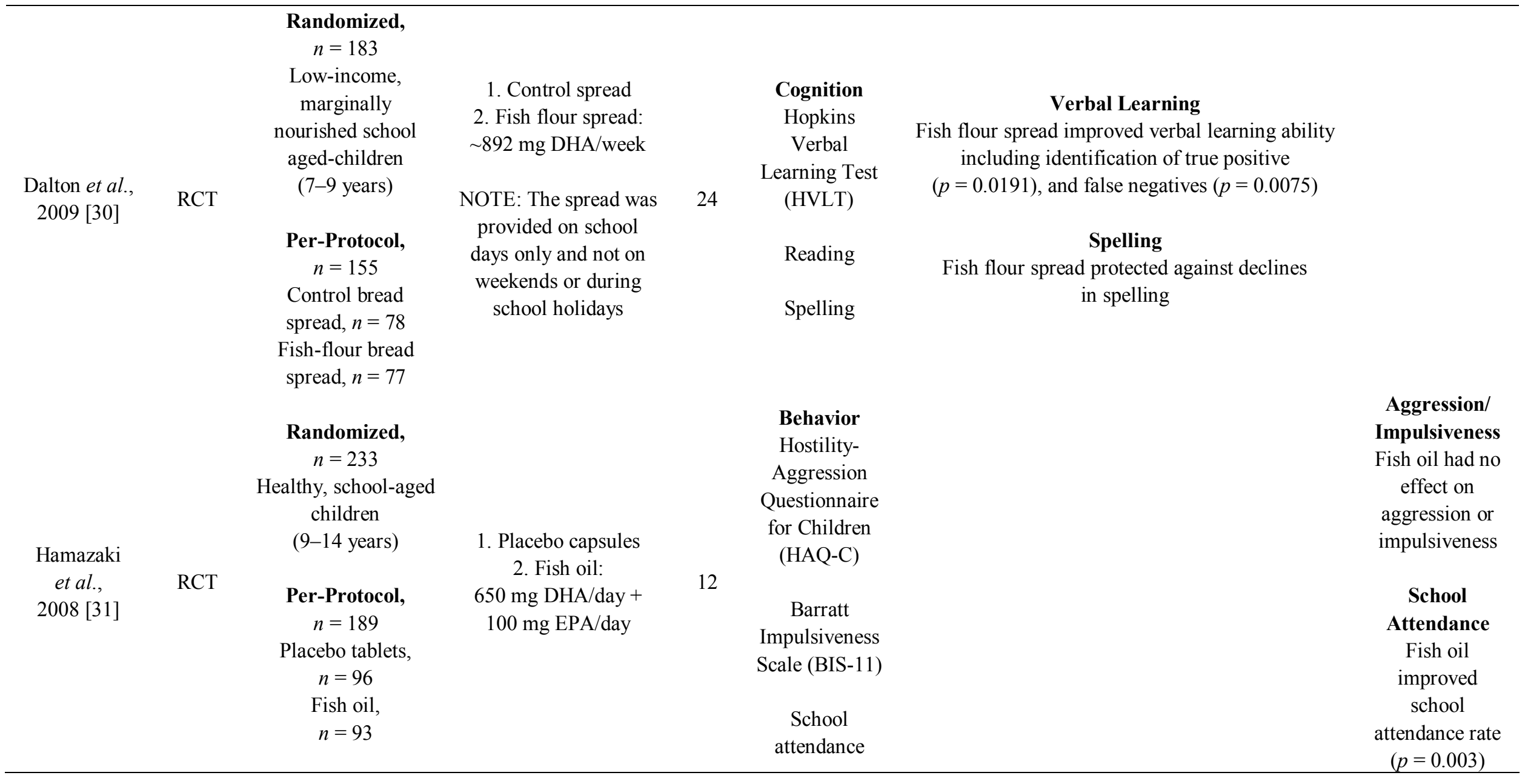


Table 2. Cont.

\begin{tabular}{|c|c|c|c|c|c|c|c|}
\hline $\begin{array}{c}\text { Itomura et al., } \\
2005 \text { [32] }\end{array}$ & $\mathrm{RCT}$ & $\begin{array}{c}\text { Randomized, } \boldsymbol{n}=\mathbf{1 7 9} \\
\text { Healthy, school-aged } \\
\text { children (9-12 years) } \\
\text { Per-Protocol, } \boldsymbol{n}=\mathbf{1 6 6} \\
\text { Control foods, } n=83 \\
\text { Fish oil fortified foods, } \\
n=83\end{array}$ & $\begin{array}{l}\text { 1. Control foods } \\
\text { 2. Fortified foods: } \\
\sim 514 \mathrm{mg} \text { DHA/day } \\
\sim 120 \mathrm{mg} \text { EPA/day }\end{array}$ & 12 & $\begin{array}{l}\text { Behavior } \\
\text { Hostility- } \\
\text { Aggression } \\
\text { Questionnaire for } \\
\text { Children } \\
\text { (HAQ-C) } \\
\text { Picture } \\
\text { Frustration } \\
\text { (PF) Study } \\
\text { Diagnostic } \\
\text { questionnaires for } \\
\text { ADHD }\end{array}$ & & $\begin{array}{c}\text { Aggression } \\
\text { Among females, fish } \\
\text { oil protected against } \\
\text { increases in aggression } \\
\text { as assessed by the } \\
\text { HAQ-C ( } p=0.008) \\
\text { Among males, } \\
\text { aggression against } \\
\text { others as assessed by } \\
\text { the PF study, increased } \\
\text { in the fish oil group but } \\
\text { not in the control group } \\
\text { Impulsivity (DSM-IV) } \\
\text { Among females, } \\
\text { fish-oil reduced } \\
\text { impulsivity ( } p=0.008 \text { ) }\end{array}$ \\
\hline $\begin{array}{l}\text { Kennedy } \\
\text { et al., } \\
2009[33]\end{array}$ & $\mathrm{RCT}$ & $\begin{array}{c}\text { Randomized } \\
n=90 \\
\text { Healthy, school-aged } \\
\text { children (10-12 years) } \\
\begin{array}{c}\text { Per-Protocol } \\
n=88\end{array} \\
\text { Placebo tablets, } n=30 \\
\text { Low-dose algal DHA, } \\
n=28 \\
\text { High-dose algal DHA, } \\
n=30\end{array}$ & $\begin{array}{c}\text { Placebo capsules } \\
\text { Algal DHA: } 400 \mathrm{mg} / \text { day } \\
\text { Algal DHA: } 1000 \mathrm{mg} / \text { day }\end{array}$ & 8 & $\begin{array}{c}\text { Cognition } \\
\text { Cognitive Drug } \\
\text { Research (CDR) } \\
\text { battery } \\
\text { Internet Battery }\end{array}$ & $\begin{array}{c}\text { CDR } \\
\text { Except for the word } \\
\text { recognition task, } \\
\text { DHA had no effect } \\
\text { on cognition } \\
\text { For the word } \\
\text { recognition task, } \\
\text { children given low- } \\
\text { dose DHA performed } \\
\text { significantly faster } \\
(p<0.05) \text { while } \\
\text { children given high- } \\
\text { dose DHA performed } \\
\text { significantly slower } \\
(p<0.05)\end{array}$ & $\begin{array}{l}\text { Internet battery } \\
\text { Except for the visual } \\
\text { analog ratings of } \\
\text { "relaxed", DHA had no } \\
\text { effect on cognition } \\
\text { For ratings of } \\
\text { "relaxed", children } \\
\text { given low and high } \\
\text { dose DHA rated } \\
\text { themselves as } \\
\text { "more relaxed" }\end{array}$ \\
\hline
\end{tabular}


Table 2. Cont.

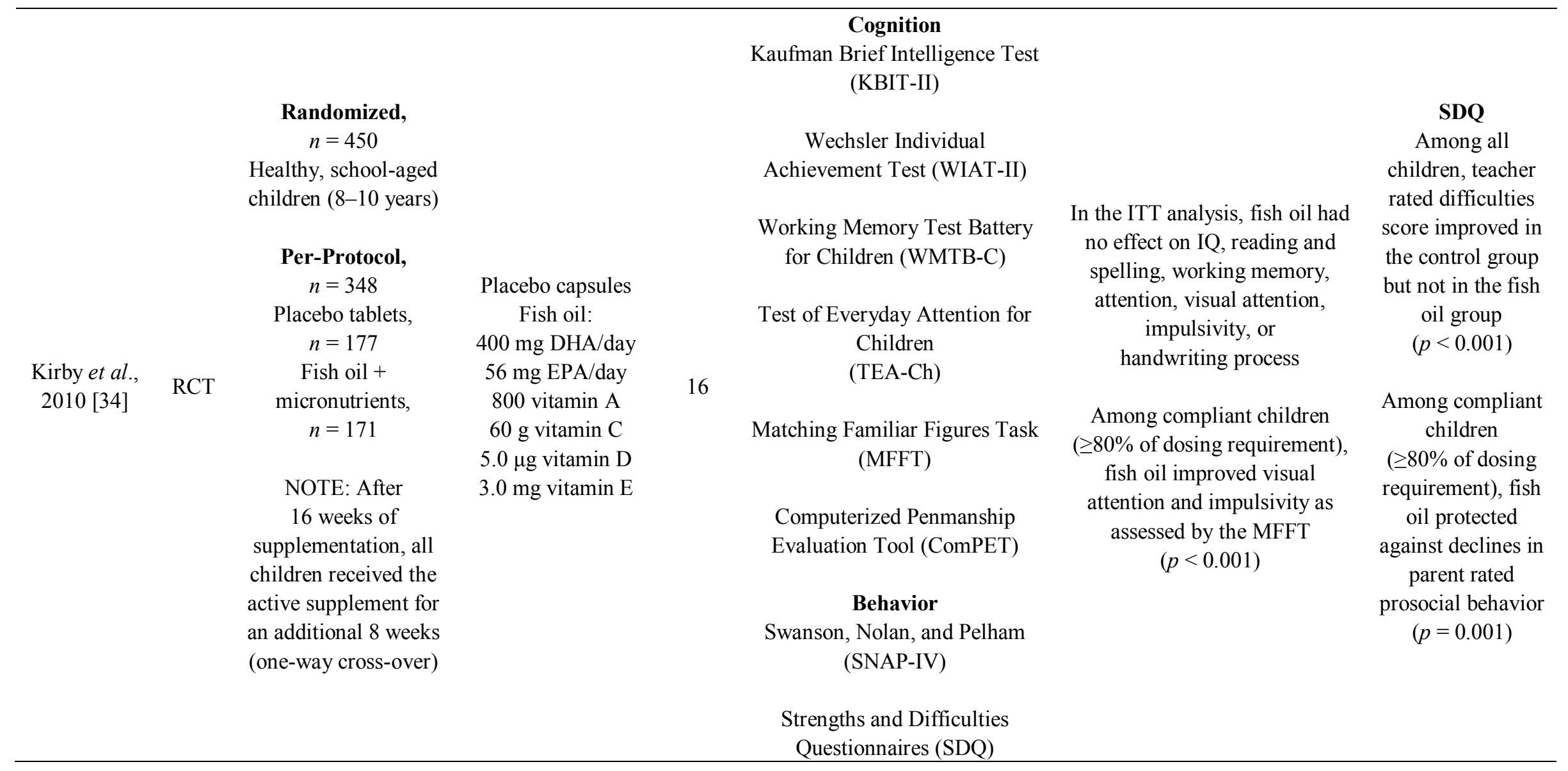


Table 2. Cont.

\begin{tabular}{|c|c|c|c|c|c|}
\hline $\begin{array}{l}\text { McNamara } \\
\text { et al., } \\
2010 \text { [12] }\end{array}$ & RCT & $\begin{array}{c}\text { Randomized } \\
n=38 \\
\text { Healthy, school-aged } \\
\text { boys (8-10 years) } \\
\\
\text { Per-Protocol } \\
n=33 \\
\text { Placebo tablets, } \\
n=10 \\
\text { Low-dose algal } \\
\text { DHA, } n=10 \\
\text { High-dose algal } \\
\text { DHA, } n=13\end{array}$ & $\begin{array}{c}\text { Placebo capsules } \\
\text { Algal DHA: } \\
400 \mathrm{mg} / \text { day } \\
\text { Algal DHA: } \\
1200 \mathrm{mg} / \text { day }\end{array}$ & $\begin{array}{c}\text { Cognition } \\
\text { Functional magnetic resonance } \\
\text { imaging (fMRI) } \\
\text { Identical-Pairs version of the } \\
\text { Continuous Performance Task } \\
\text { (CPT-IP) }\end{array}$ & $\begin{array}{l}\text { Whole-brain activation } \\
\text { patterns during performance } \\
\text { of sustained attention tasks } \\
\text { Low-dose DHA improved brain } \\
\text { activation (increased activation } \\
\text { in the dorsolateral prefrontal } \\
\text { cortex, decreased activation in } \\
\text { the occipital cortex) } \\
\text { High-dose DHA improved brain } \\
\text { activation (increased activation } \\
\text { in the dorsolateral prefrontal } \\
\text { cortex, decreased activation in } \\
\text { the cerebellar cortex) } \\
\text { Erythrocyte DHA positively } \\
\text { correlated with dorsolateral } \\
\text { prefrontal cortex activation } \\
\text { Sustained attention } \\
\text { Low- and high-dose DHA had } \\
\text { no effect on sustained attention } \\
\text { performance } \\
\text { Erythrocyte DHA inversely } \\
\text { correlated with reaction time on } \\
\text { the sustained attention test } \\
(p=0.02)\end{array}$ \\
\hline
\end{tabular}


Table 2. Cont.

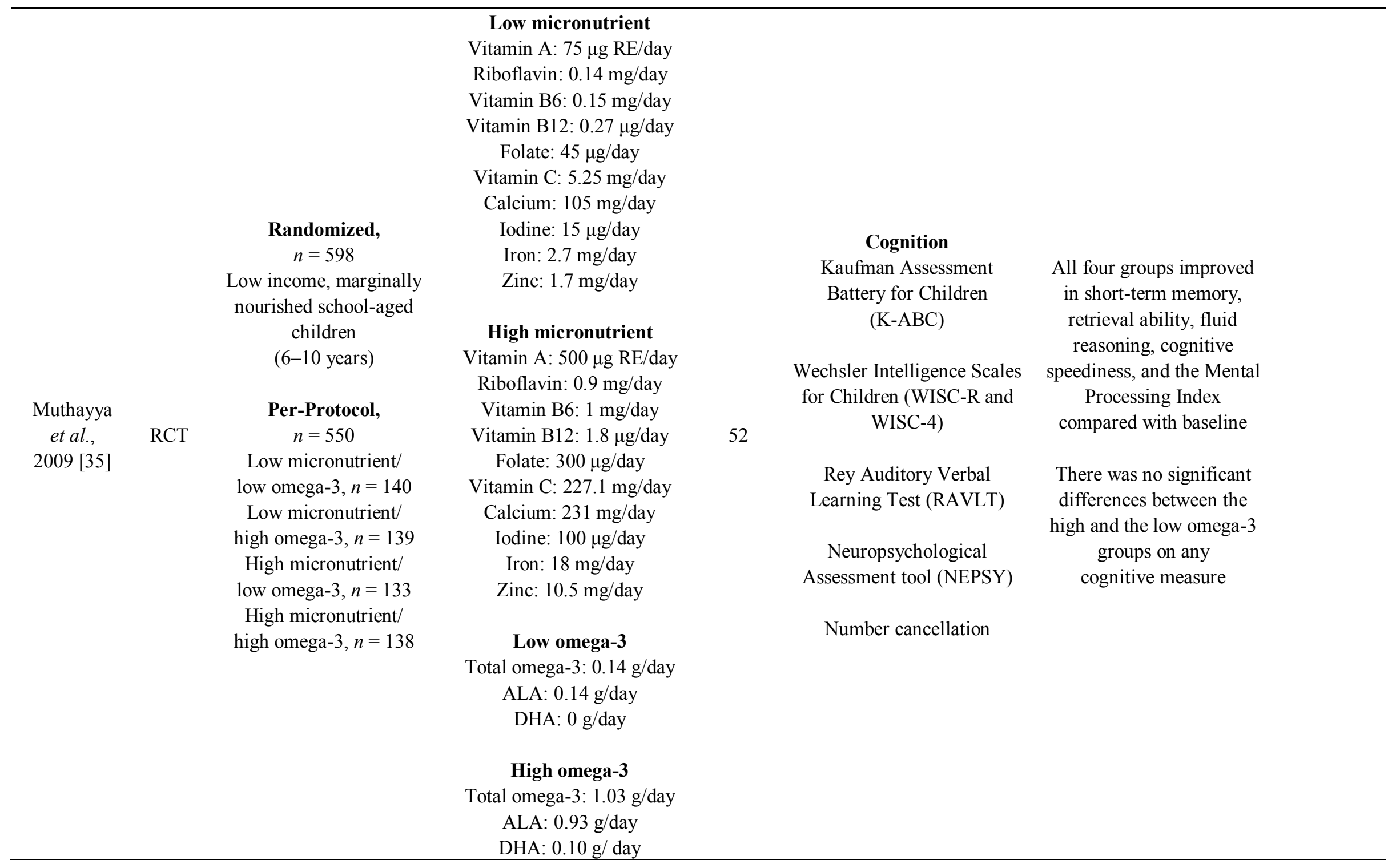


Table 2. Cont.

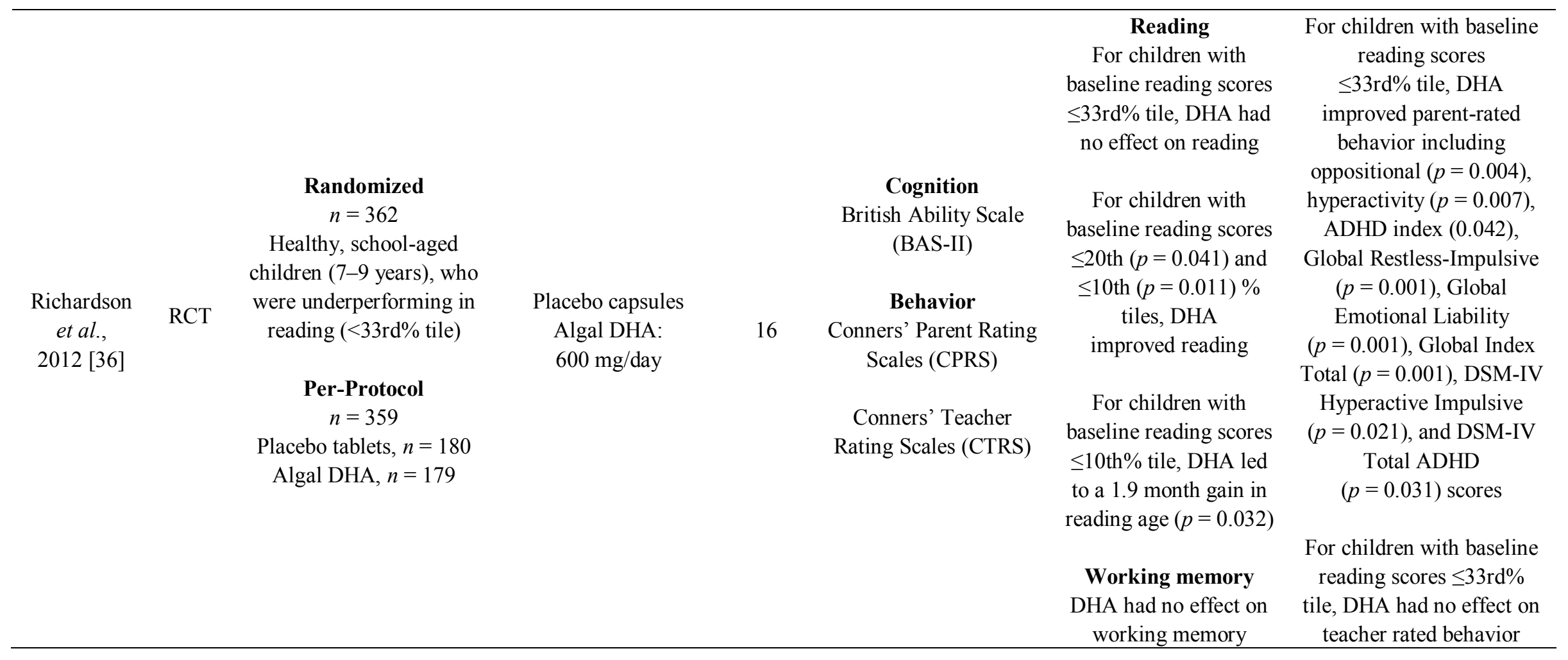


Table 2. Cont.

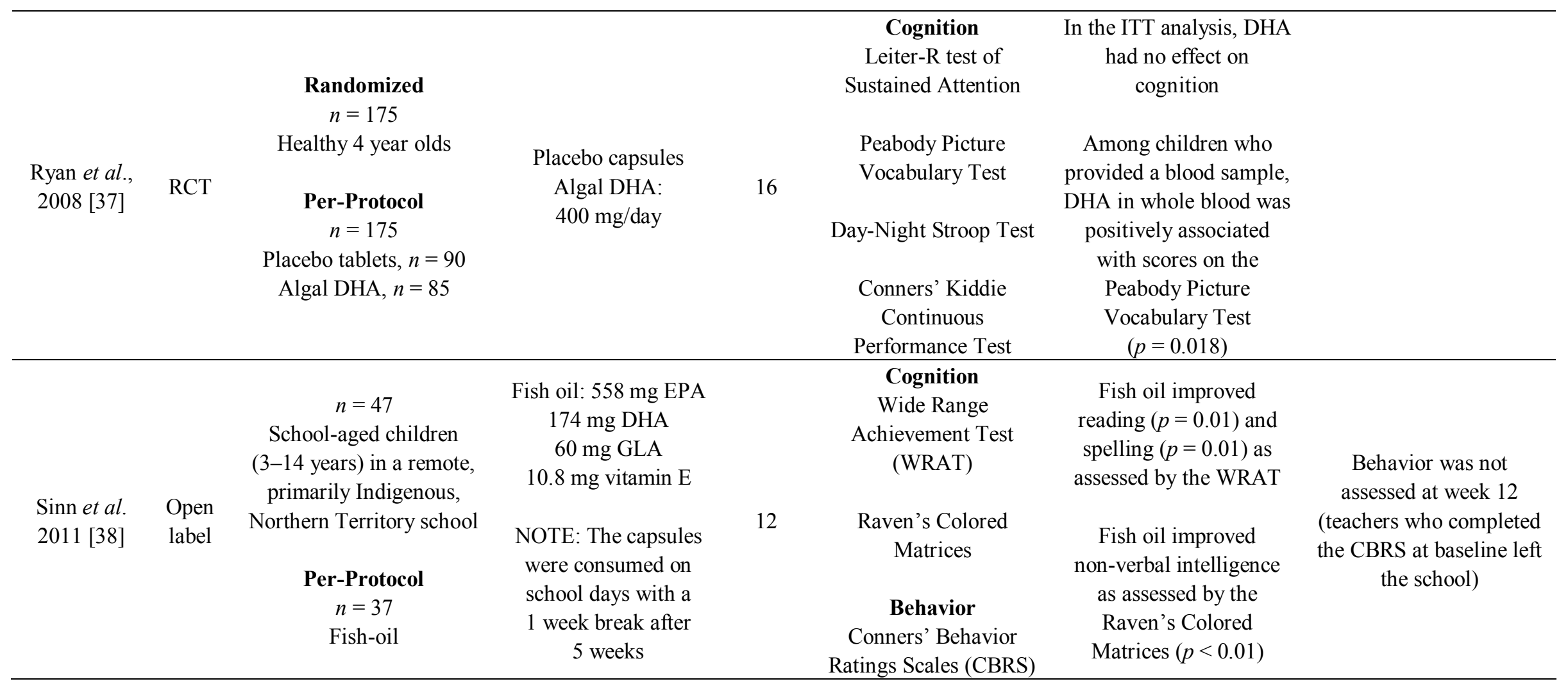


Table 2. Cont.

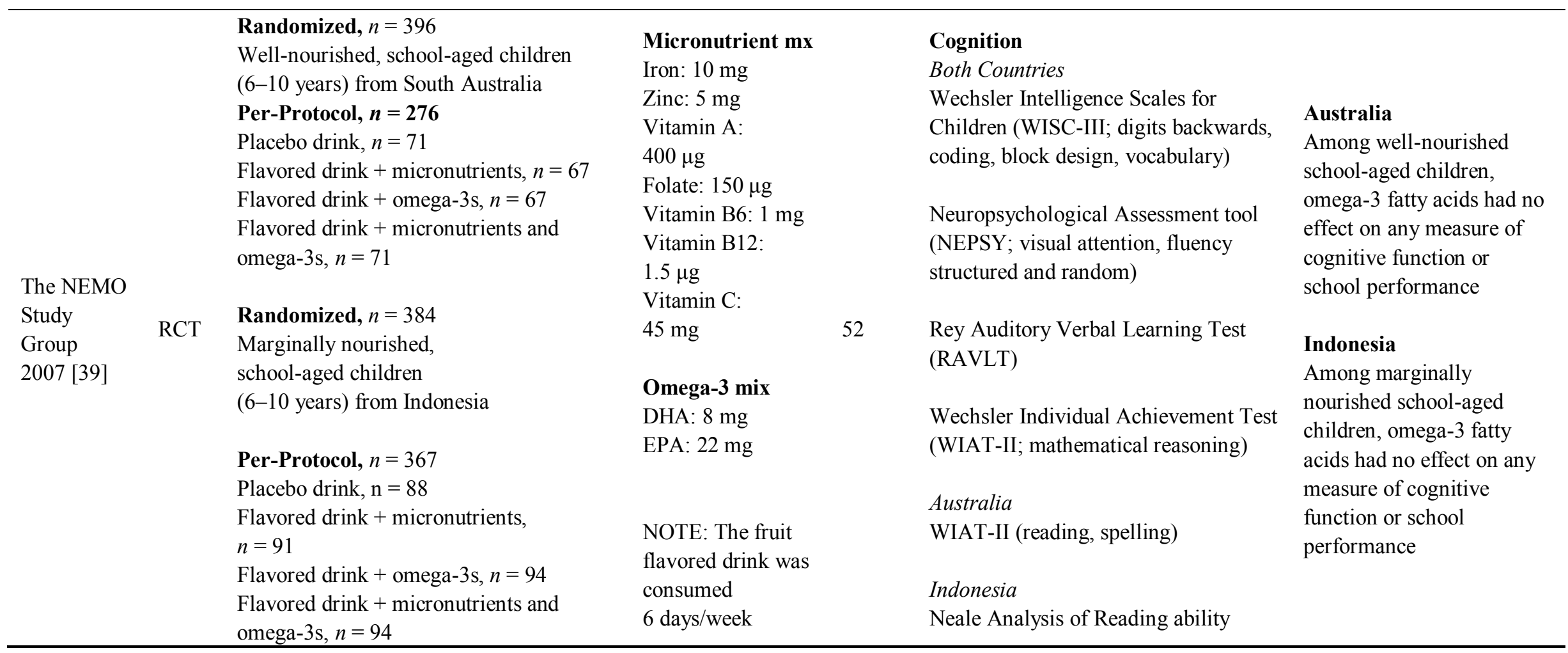

Abbreviations: Barratt Impulsiveness Scale (BIS-II), British Ability Scale (BAS), Cognition Drug Research (CDR), Computerized Penmanship Evaluation Tool (ComPET), Conners' Behavior Ratings Scales (CBRS), Conners' Parent Rating Scales (CPRS), Conners' Teacher Rating Scales (CTRS), Functional Magnetic Resonance Imaging (fMRI), Hostility-Aggression Questionnaire for Children (HAQ-C), Hopkins Verbal Learning Test (HVLT), Identical-Pairs verson of the Continuous Performance Task (CPT-IP), Intention-to-treat (ITT), Kaufman Assessment Battery (K-ABC), Kaufman Brief Intelligence Test (KBIT), Matching Familiar Figures Task (MFFT), Neuropsychological Assessment tool (NEPSY), Picture Frustration (PF), Ray Auditory Verbal Learning Test (RAVLT), Strengths and Difficulties Questionnaire (SDQ), Swanson, Nolan, and Pelham (SNAP), Test of Everyday Attention for Children (TEA-Ch), Wechsler Individual Achievement Test (WIAT), Wechsler Intelligence Scales for Children (WISC), Wide Range Achievement Test (WRAT), Working Memory Test Battery for Children (WMTB-C). 
Table 3. DHA status reported in clinical trials of DHA supplementation in children.

\begin{tabular}{|c|c|c|c|c|c|c|}
\hline Reference & Time Point & \multicolumn{2}{|r|}{ Placebo } & \multicolumn{2}{|c|}{ Treatment } & Biomarker \\
\hline \multirow{6}{*}{$\begin{array}{c}\text { Dalton et al., } \\
2009[30]\end{array}$} & Baseline & \multirow{2}{*}{\multicolumn{2}{|c|}{$2.81 \pm 0.70$}} & \multirow{2}{*}{\multicolumn{2}{|c|}{$3.71 \pm 0.66$}} & \multirow{2}{*}{$\%$ of total fatty acids (PC in RBCs) } \\
\hline & Endpoint & & & & & \\
\hline & Baseline & \multirow{2}{*}{\multicolumn{2}{|c|}{$7.77 \pm 2.16$}} & & & \multirow{2}{*}{$\%$ of total fatty acids (PE in RBCs) } \\
\hline & Endpoint & & & & & \\
\hline & Baseline & \multirow{2}{*}{\multicolumn{2}{|c|}{10.58}} & & & \multirow{2}{*}{$\%$ of total fatty acids $(\mathrm{PC}+\mathrm{PE}$ in $\mathrm{RBCs})$} \\
\hline & Endpoint & & & & \\
\hline \multirow{2}{*}{$\begin{array}{c}\text { Hamazaki et al., } \\
2008[31]\end{array}$} & Baseline & \multicolumn{2}{|r|}{$4.4 \pm 0.9$} & \multirow{2}{*}{\multicolumn{2}{|c|}{$\begin{array}{l}4.4 \pm 1.1 \\
7.8 \pm 1.1\end{array}$}} & \multirow{2}{*}{$\begin{array}{l}\% \text { of total fatty acids (phospholipid fraction } \\
\text { in RBCs) }\end{array}$} \\
\hline & Endpoint & \multicolumn{2}{|r|}{$4.9 \pm 1.2$} & & & \\
\hline \multirow{2}{*}{$\begin{array}{l}\text { Itomura et al., } \\
2005[32]\end{array}$} & Baseline & \multicolumn{2}{|r|}{$6.4 \pm 0.9$} & \multicolumn{2}{|c|}{$6.1 \pm 0.9$} & $\%$ of total fatty acids (phospholipid fraction \\
\hline & Endpoint & \multicolumn{2}{|r|}{$6.6 \pm 0.9$} & \multicolumn{2}{|c|}{$7.1 \pm 1.8$} & in RBCs) \\
\hline \multicolumn{4}{|l|}{$\begin{array}{c}\text { Kennedy et al., } \\
2009[33]\end{array}$} & \multicolumn{2}{|c|}{ NR } & \\
\hline \multirow{2}{*}{$\begin{array}{c}\text { Kirby et al., } \\
2010[34]\end{array}$} & Baseline & \multicolumn{2}{|r|}{$0.07 \pm 0.007$} & \multicolumn{2}{|c|}{$0.08 \pm 0.009$} & $\%$ of total fatty acid methyl esters (buccal \\
\hline & Endpoint & \multicolumn{2}{|r|}{$0.20 \pm 0.16$} & \multicolumn{2}{|c|}{$0.37 \pm 0.23$} & cell sample) \\
\hline \multicolumn{4}{|l|}{$\begin{array}{l}\text { Richardson et al., } \\
\quad 2012[36]\end{array}$} & \multicolumn{2}{|c|}{ NR } & \\
\hline \multirow{2}{*}{$\begin{array}{c}\text { Ryan et al., } \\
2008[37]\end{array}$} & Baseline & \multirow{2}{*}{\multicolumn{2}{|c|}{$\begin{array}{l}1.0 \pm 0.34 \\
1.1 \pm 0.40\end{array}$}} & \multirow{2}{*}{\multicolumn{2}{|c|}{$\begin{array}{l}1.0 \pm 0.34 \\
3.3 \pm 1.54\end{array}$}} & 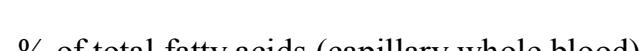 \\
\hline & Endpoint & & & & & \% or total ralty acias (capinary wnore orood) \\
\hline \multicolumn{2}{|l|}{$\begin{array}{l}\text { Sinn et al., } \\
2011[38]\end{array}$} & \multicolumn{4}{|c|}{ NR } & \\
\hline Baumgartner et al., & & Placebo & Iron & DHA/EPA & $\begin{array}{c}\text { Iron }+ \\
\text { DHA/EPA }\end{array}$ & \\
\hline $2012[29]$ & Baseline & $3.07 \pm 0.69$ & $3.07 \pm 0.64$ & $3.05 \pm 0.63$ & $3.01 \pm 0.58$ & $\%$ of total fatty acids (phospholipid fraction \\
\hline & Endpoint & $3.79 \pm 0.96$ & $3.83 \pm 1.06$ & $5.94 \pm 1.71$ & $5.90 \pm 2.11$ & in RBCs) \\
\hline
\end{tabular}


Table 3. Cont

\begin{tabular}{|c|c|c|c|c|c|c|}
\hline \multirow{3}{*}{$\begin{array}{l}\text { McNamara et al., } \\
\quad 2010 \text { [12] }\end{array}$} & \multirow{3}{*}{$\begin{array}{l}\text { Baseline } \\
\text { Endpoint }\end{array}$} & \multicolumn{2}{|c|}{ Placebo } & \multirow{3}{*}{$\begin{array}{c}\text { Low Dose } \\
\text { Treatment } \\
3.3 \pm 1.3 \\
7.5 \pm 1.3 \\
\end{array}$} & \multirow{3}{*}{$\begin{array}{c}\text { High Dose } \\
\text { Treatment } \\
3.3 \pm 1.3 \\
10.3 \pm 1.5 \\
\end{array}$} & \multirow{3}{*}{$\%$ of total fatty acids (RBC) } \\
\hline & & \multicolumn{2}{|c|}{$3.3 \pm 1.3$} & & & \\
\hline & & \multicolumn{2}{|c|}{$2.5 \pm 1.6$} & & & \\
\hline \multirow{4}{*}{$\begin{array}{l}\text { Muthayya et al., } \\
\quad 2009 \text { [35] }\end{array}$} & & Low Micro/ & Low Micro/ & High Micro/ & High Micro/ & \multirow{4}{*}{$\begin{array}{l}\% \text { of total fatty acids (phospholipid fraction } \\
\text { in RBCs) }\end{array}$} \\
\hline & & Low Omega-3 & High Omega-3 & Low Omega-3 & High Omega-3 & \\
\hline & Baseline & $3.3 \pm 0.9$ & $3.2 \pm 0.9$ & $3.2 \pm 0.8$ & $3.2 \pm 0.7$ & \\
\hline & Endpoint & $3.6 \pm 1.0$ & $5.2 \pm 1.2$ & $3.6 \pm 0.8$ & $5.2 \pm 1.2$ & \\
\hline \multirow{3}{*}{$\begin{array}{c}\text { The NEMO Study } \\
\text { Group } \\
2007[39]\end{array}$} & & Placebo & Micronutrients & DHA/EPA & Micronutrients & \multirow[b]{3}{*}{ Plasma $(\mu \mathrm{g} / \mathrm{mL})$} \\
\hline & Baseline & $332+110$ & $352+104$ & $311+106$ & + DHA/EPA & \\
\hline & Endpoint & $38.4 \pm 14.0$ & $36.8 \pm 8.5$ & $47.4 \pm 12.7$ & $47.4 \pm 10.7$ & \\
\hline
\end{tabular}

Abbreviations: Red blood cells (RBCs), Phosphatidylcholine (PC), Phosphatidylethanolamine (PE), Not reported (NR). 
Five of the included studies, or study arms, were conducted in populations of children with multiple nutrient deficiencies [29,30,35,38,39]. It is commonly known that many nutrients other than DHA affect neurological development and cognition in children. Although the question has been raised, it is unknown to what extent cognitive function can be affected based on replenishment of $n$-3 LC-PUFA alone in the case of generalized malnutrition [40]. Further investigation of this question should be considered in future studies. However, since the studies met the pre-defined inclusion criteria for this review by enrolling children without a neuropsychological diagnosis, and analyzing data in a $n$-3 LC-PUFA specific manner, those studies conducted in populations with an increased incidence of malnutrition were included in this review.

The number of subjects varied greatly among the studies, ranging from 33 in the study by McNamara et al. [12] to 598 in the study by Muthayya et al. [35]. Study duration was also variable and ranged from 2 [33] to 12 months [35,39]. Many of the studies reported results as analyzed both in the "intention to treat" as well as the "per protocol" subject groups, and most reported results as a degree of change from baseline. Compliance was monitored and assessed in all studies and many authors acknowledged the difficulty associated with supplement protocols that often involved subjects, parents, caregivers, and teachers.

The accepted studies included a wide number of assessments of cognition and behavior. All measures were included in this review in order to represent the broadest possible assessment from the limited number of studies. Outcome measures included objective and subjective methodologies including: electrical potential readings and functional magnetic resonance imaging; standardized tests of cognition, including reading, spelling, listening comprehension, memory, attention, and IQ; as well as self- ,parent-, and teacher-assessed behavioral questionnaires. While outcomes were often reported in relation to total omega- 3 fatty acids, ALA, or ratios of $n-3$ and $n-6$ fatty acids, the focus of this review was to determine the effect of DHA, specifically, on cognitive and behavioral outcomes.

Perhaps most interesting were the results of DHA supplementation on school performance as reported in seven of the studies [12,27,30,34,36,37,39]. Of the seven studies, five reported that DHA status or supplementation improved measures of school performance including learning ability, reading, and spelling as assessed by sub-tests of cognitive batteries [12,27,30,36,37] while two, in contrast, found no effect $[34,39]$. Two studies directly assessed brain activity and both reported benefit as the result of DHA intake or status [12,27]. Behavioral outcomes were measured in six studies [28,31-34,36], with five reporting at least one significant improvement related to DHA supplementation or status [28,32-34,36].

\subsection{Review of Studies}

Below are brief summaries of the included studies. Three of the studies were observational in design, seven were clinical studies that provided a lipid intervention, and five were clinical studies that provided other nutrients in addition to a lipid intervention.

\subsubsection{Observational Studies}

In 2003, Bakker et al. [26] reported results of a prospective, longitudinal study investigating the relationship of cognitive performance at 7 years of age with current fatty acid status and fatty acid 
status at birth. A total of 306 children with available cord blood samples were followed up at age 7 for assessments of cognitive function and achievement using the Kaufman Assessment Battery for Children $(\mathrm{K}-\mathrm{ABC})$. The investigators found no association between cord or plasma DHA and cognitive performance in the 7 year olds.

In 2011, Boucher et al. [27] reported results from a prospective, longitudinal study examining the effect of prenatal and childhood intake of DHA on memory function in school-aged children from Arctic Quebec. A total of 154 children aged 10-13 years, who had available umbilical cord blood samples, constituted the study population. Visual recognition memory was assessed by event-related potentials (ERPs) recordings during performance of a continuous recognition memory task. Memory was also assessed via a battery of neuropsychological tests including the "Digit span forward" subtest of the Wechsler Intelligence Scales for Children, 4th edition (WISC-IV) and The California Verbal Learning Test-Children's Version (CVLT). Current blood samples, along with cord blood samples, were analyzed for DHA. The pattern of ERP recordings showed that higher prenatal DHA status positively affected visual information processing and brain activity in later childhood; and, that current DHA intake was positively associated with brain activity during performance of a specific task requiring familiarity processing. Higher cord blood DHA was associated with better performance on both the 'Digit span forward' test and the CVLT suggesting better memory development. Neither cord-nor current-DHA blood levels were associated with any of the tasks of continuous recognition memory.

Kirby et al. [28] reported results of a cross-sectional study examining the relationship between cheek cell fatty acids and multiple assessments of learning, and behavior in 411 children aged 8-10 years. Assessments included: the Kaufman Brief Intelligence Test (KBIT-2) to assess verbal and non-verbal IQ; the Working Memory Test Battery for Children (WMTB-C) to assess working memory; and, the Wechsler Individual Achievement Test (WIAT-II) to assess reading and spelling ability. Test of Everyday Attention for Children (TEA-Ch) assessed attention capabilities; and, visual attention and impulsivity were assessed using the Matching Familiar Figures Task (MFFT). Aspects of behavior were assessed by parents and teachers using the Swanson, Nolan, and Pelham (SNAP-IV) and the Strengths and Difficulties Questionnaire (SDQ) scales; parents also completed the Developmental Coordination Disorder Questionnaire (DCDQ). Results revealed a positive association of cheek cell DHA with non-verbal IQ and a negative association with teacher rating of hyperactivity and total difficulties.

\subsubsection{Clinical Studies (Lipid-Only Intervention)}

Seven of the studies which met inclusionary criteria were randomized, clinical trials that included supplementation with either fish oil or algal oil as a source of DHA. Ryan and Nelson [37], reported results of a multi-center RCT designed to determine the effects of DHA supplementation on cognition in children. A total of 175 healthy, 4 year olds were supplemented with $400 \mathrm{mg}$ DHA/day or placebo for 4 months. Cognitive function was measured using the Leiter-R test of Sustained Attention (Leiter-R SA), the Peabody Picture Vocabulary Test (PPVT), the Day-Night Stroop Test (DNST), and the Conners' Kiddie Continuous Performance Test (Conners' KCPT). Results showed no effect of DHA supplementation on any of the tests of cognitive function. There was a reported ceiling effect on 
the Leiter-R SA and the DNST in the children tested, (i.e., a significant number of children had high level scores at baseline leaving little ability to show improvement on the tests) which likely influenced the results. Interestingly, a pre-planned analysis of 93 children showed a significant and positive association of whole-blood DHA and PPVT scores.

An RCT by McNamara et al. [12] was designed to determine the effects of DHA supplementation on functional cortical activity during sustained attention in healthy boys. A total of 33 healthy boys aged 8-10 years were supplemented with 400 or $1200 \mathrm{mg}$ DHA/day, or a matching placebo for 8 weeks. The primary outcome included change from baseline in cortical activation patterns, as measured by functional magnetic resonance imaging (fMRI). fMRI scans were recorded at baseline and after 8 weeks of supplementation and whole-brain activation patterns were determined during a task of sustained attention. Results of the study confirmed that 8 weeks of supplementation with either low- or high-dose DHA significantly increased functional activation in the dorsolateral prefrontal cortex (DLPFC) during performance of the sustained-attention task (CPT-IP) as compared to placebo. The authors reported a ceiling effect for the CPT-IP task with an $80 \%-90 \%$ accuracy rate exhibited by all groups and, therefore, performance of the DHA-supplemented children on the CPT-IP did not differ from controls. However, the children's erythrocyte DHA was positively correlated with DLPFC activation and inversely correlated with reaction time during the attention task.

In an RCT by Kennedy et al. [33], 90 healthy children aged 10-12 years were supplemented with 400 or $1000 \mathrm{mg}$ DHA/day, or a matching placebo for 8 weeks. Cognition and mood were assessed using two batteries of computer-based cognitive tests, the Cognitive Drug Research Battery (CDR) and the Internet Battery. The authors reported no consistent cognitive benefit as assessed by the CDR as a result of DHA supplementation. After 8 weeks, children supplemented with $400 \mathrm{mg}$ DHA/day performed faster on word recognition tasks than children given placebo while those supplemented with $1000 \mathrm{mg}$ DHA/day performed slower than children given placebo. In addition, performance on the Internet Battery did not differ by treatment group except for the visual analogue measure of "relaxed", where children supplemented with both $400 \mathrm{mg}$ and $1000 \mathrm{mg}$ DHA/day showed greater improvement from baseline than controls. The validity of this difference is questionable since the groups differed significantly on this measure at baseline.

The study by Dalton et al. [30] was a randomized, single-blind, placebo-controlled clinical study investigating the effect of a spread, rich in omega-3 fatty acids, on cognition in children. A total of 183 low-income, marginally nourished schoolchildren aged 7-9 years were given a bread spread containing marine fish flour or an analogous spread without fish flour. Children were given the spread on two slices of bread per day, on school days, for 6 months. The fish flour spread provided $\sim 892 \mathrm{mg}$ of DHA/week. The primary outcomes were change from baseline on scores from the Hopkins Verbal Learning Test battery (HVLT), a reading test, and a spelling test. After 6 months, children supplemented with fish flour spread performed better on the HVLT compared to unsupplemented children, scoring higher on measures of recognition and discrimination. Children consuming the $n-3$ spread did not experience the decline in spelling observed in the unsupplemented children over the 6 months, and there was a marginally significant benefit of supplementation on reading.

Two studies investigated the effect of omega-3 supplementation on behavior, exclusively $[31,32]$. Hamazaki et al. [31] reported results from an RCT in healthy school children from Lampung Province, Indonesia. A total of 233 children aged 9-14 years were supplemented with DHA-rich fish oil 
containing $650 \mathrm{mg}$ DHA and $100 \mathrm{mg}$ EPA/day or placebo for 3 months. Aggression and impulsivity were assessed using the Hostility-Aggression Questionnaire for Children (HAQ-C) and the Barratt Impulsiveness Scale, version 11 (BIS-11). School attendance was recorded as well. While school attendance was higher in the DHA group, no behavioral benefit as the result of supplementation was found.

Itomura et al. [32] reported findings from an RCT investigating the effect of omega-3 fatty acid supplementation on behavior (aggression) in healthy school children from Japan. A total of 179 healthy children aged 9-12 years were given fish oil-fortified foods (rolls, bread, sausage, and spaghetti) providing approximately $3600 \mathrm{mg}$ DHA/week ( $\sim 514 \mathrm{mg} /$ day) plus $840 \mathrm{mg} \mathrm{EPA} /$ week ( $\sim 120 \mathrm{mg}$ /day) or similar unfortified foods for 3 months. Aggression was assessed using the HAQ-C and the Picture Frustration (PF) Study. Attention deficit, hyperactivity and impulsivity were assessed by parents/guardians using diagnostic questionnaires of DSM-IV for ADHD. After 3 months of supplementation, DHA-rich fish oil-fortified foods protected against increases in aggression (as assessed by the HAQ-C). Specifically, in a per-protocol analysis, HAQ-C or physical aggression, scores increased significantly between baseline and week 12 in the female placebo group, but remained unchanged in the female active treatment group. Supplementation was also associated with reduced impulsivity among females as assessed by parents/guardians. No significant changes in assessment of aggression or impulsivity were observed in males, however.

Richardson et al. [36] reported the results of an RCT designed to determine the effects of dietary supplementation with DHA on reading, working memory, and behavior in healthy schoolchildren. A total of 362 healthy children aged 7-9 years who were underperforming in reading (below the 33rd percentile/equivalent to $\sim 18$ months behind chronological age) were enrolled in the study. Subjects were supplemented with $600 \mathrm{mg}$ DHA/day or a matching placebo for 16 weeks. The primary outcome measures were reported as change from baseline in reading, working memory, and behavior. Reading was assessed using the Word Reading Achievement sub-test of the British Ability Scale (BAS II). Working memory was assessed using two sub-tests of the BAS II (Recall of Digits Forward and Recall of Digits Backward), and behavior was assessed by parents or guardians and teachers using the Conners' Ratings Scales (CPRS and CTRS respectively). After 16 weeks of supplementation, performance on the reading test did not differ by treatment. However, in a pre-planned analysis of 224 children with baseline reading scores $\leq 20$ th percentile, and in the subgroup of 105 children with baseline reading scores $\leq 10$ th percentile, DHA supplementation significantly improved reading. DHA supplementation also improved reading age, above the expected 4 month gain over the 16 week study period. For children with baseline readings scores $\leq 20$ th percentile, DHA supplementation led to an additional 0.8 month gain in reading age (approximately 20\% greater than expected). For children with baseline reading scores $\leq 10$ th percentile, supplementation resulted in an additional 1.9 month gain in reading age (approximately 50\% greater than expected. DHA also significantly improved behavior as rated by parents. Compared to children given placebo, children supplemented with DHA experienced significant improvements in eight of fourteen scales of the CPRS. No effects were seen on behavior as rated by the teachers and there were no significant effects of supplementation on memory. 


\subsubsection{Clinical Studies (Multiple Nutrient Interventions)}

Five studies included supplementation with either fish oil or algal oil as a source of DHA in addition to other fatty acids and/or micronutrients [29,34,35,38,39]. The RCT by Muthayya et al. [35] compared the effects of a combination of micronutrients and omega-3 fatty acids on indicators of cognitive performance in low-income, marginally nourished schoolchildren in Bangalore, India. A total of 598 children aged 6-10 years were allocated to 1 of 4 intervention groups to receive foods fortified with micronutrients at either a high (100\% RDA) or low (15\% RDA) level in combination with either $930 \mathrm{mg} \mathrm{ALA}$ /day plus $100 \mathrm{mg}$ DHA/day (high omega-3) or $140 \mathrm{mg}$ ALA/day (low omega-3) for 12 months. The four groups were defined as: high micronutrients, high omega-3; low micronutrients, high omega-3; high micronutrients, low omega-3; or, low micronutrient, low omega-3. The cognitive test battery consisted of 11 sub-tests to evaluate: fluid reasoning; short-term memory; retrieval ability; and, cognitive speediness. Outcomes were measured at baseline and after 6 and 12 months of supplementation. After 12 months, all 4 groups had significant improvements in short-term memory, retrieval ability, fluid reasoning, cognitive speediness, and overall cognitive performance. Analyses showed differences in cognitive scores according to micronutrient supplementation, but no differences were detected related to DHA or other omega-3 fatty acid supplementation.

Kirby et al. [34] reported the results of a one-way crossover design RCT investigating the effect of omega-3 fatty acid supplementation on cognition and behavior in healthy schoolchildren from a mainstream school population. A total of 450 healthy children aged 8-10 years were supplemented with $400 \mathrm{mg} \mathrm{DHA}+56 \mathrm{mg}$ EPA/day plus other micronutrients or placebo for 16 weeks. Following 16 weeks of supplementation, both groups received the active supplement for an additional 8 weeks. Outcomes included verbal and non-verbal IQ as measured by the KBIT-2, reading and spelling ability as measured by the WIAT-II, working memory as measured by the WMTB-C, attention as measured by the TEA-Ch, and visual attention and impulsivity as measured by the MFFT. In addition, handwriting process was measured using the Computerized Penmanship Evaluation Tool (ComPET), and parent- and teacher-rated behavior was assessed using the SNAP-IV and SDQ. Results showed that performance on the cognitive tests did not differ by treatment group. However, in a per-protocol analysis of the 235 children who reached compliance criteria, DHA supplementation significantly improved visual attention and impulsivity as assessed by the MFFT. The number of first correct responses was significantly higher in the active treatment group compared to the placebo group. With regard to behavior in the per-protocol analysis, supplementation protected against declines in parent-rated pro-social behavior. In the intention-to-treat analysis, however, teachers saw improvement in the "difficulties" score in unsupplemented children only.

Sinn et al. [38] reported results from an open-label pilot study designed to investigate the feasibility of providing fish oil supplements to children in a remote, Northern Territory school in Australia. A total of 47 children, aged 3-14 years, were given a supplement during school days providing $558 \mathrm{mg}$ EPA + $174 \mathrm{mg}$ DHA, plus $60 \mathrm{mg}$ GLA, plus $10.8 \mathrm{mg}$ vitamin E/day for 12 weeks. Reading and spelling were assessed using the Wide Range Achievement Test (WRAT); non-verbal intelligence was assessed using the Raven's Colored Matrices; and behavior was assessed by teachers using the Conners' Behavior Ratings Scales (CBRS). Outcomes were measured at baseline and after 12 weeks. After 12 weeks of supplementation, reading and spelling scores and performance on the Raven's 
Coloured Matrices improved significantly. It is important to note, however, that this pilot study was not placebo-controlled and the observed changes may not be due to supplementation.

The Nutrition Enhancement for Mental Optimization (NEMO) study group [39] reported results of a RCT which assessed the effect of micronutrients, long-chain omega-3 fatty acids, or both on cognitive performance in well-nourished and marginally nourished children age 6-10 years. A total of 396 well-nourished children from Adelaide, South Australia, and a total of 384 marginally nourished children from Jakarta, Indonesia, were enrolled in the study. Children received a fruit-flavored drink containing: a micronutrient mix alone; an omega-3 fatty acid mix alone; a combination of the micronutrient and omega-3 fatty acid mixes; or a placebo mix. The fruit-flavored drink was consumed 6 days/week for 12 months. The micronutrient mix provided 100\% of the RDA for iron, folate, vitamin B6, vitamin B12, vitamin A, and vitamin $\mathrm{C}$ and $50 \%$ of the RDA for zinc. The omega-3 fatty acid mix provided $88 \mathrm{mg}$ DHA/day and $22 \mathrm{mg}$ EPA/day. Cognitive function and school performance were assessed after 6 and 12 months of supplementation using a series of standardized neuropsychological tests. Subjects from the two test sites were different with regard to several characteristics including nutritional status; therefore data for Indonesia and Australia were analyzed separately. From the Australian site, results showed that in well-nourished, school-aged children, 12 months of supplementation with multiple micronutrients improved verbal learning and memory, but had no effect on tests of general intelligence or attention. Supplementation with omega-3 fatty acids did not affect cognitive function or school performance. In the Indonesian children who were marginally nourished, results showed that fortification with multiple micronutrients improved verbal learning and memory in girls but not in boys. As in the Australian cohort, omega-3 fatty acids had no effect on any measure of cognitive function or school performance.

Baumgartner et al. [29] reported the findings of an RCT investigating the effects of iron and DHA/EPA supplementation alone and in combination, in children with poor iron and omega-3 fatty acid status. A total of 321 children, aged 6-11 years, with iron deficiency were allocated to receive iron, DHA/EPA, iron plus DHA/EPA, or a matching placebo 4 days/week for 34 weeks. Iron was provided at a dose of $50 \mathrm{mg} /$ day and fish oil was provided at a dose of $420 \mathrm{mg}$ DHA/day and $80 \mathrm{mg}$ EPA/day. Because supplementation was interrupted by holidays and teacher strikes, supplements were provided for 105 days. Mean total iron intake over the 105 day supplementation period was $4.8 \mathrm{~g}$ (45.7 mg/day). Mean total DHA intake was $41.2 \mathrm{~g}$ (392 mg/day), and mean total EPA intake was $7.8 \mathrm{~g}$ ( $74 \mathrm{mg} /$ day). The primary outcome measures were change from baseline in tests of cognition including 4 subtests of the Kaufman Assessment Battery for Children (KABC-II) and the Hopkins Verbal Learning Test (HVLT). Results of the study indicated that while children supplemented with iron performed better than un-supplemented children on the HVLT test of learning and memory, DHA/EPA supplementation had no effect on learning or memory. Results of the study also found that in a sub-group analysis stratified by anemia status, children with iron deficiency anemia supplemented with DHA/EPA performed significantly worse than children given placebo on the KABC-II test of long-term memory. In a second sub-group analysis stratified by sex, there was a significant negative effect of DHA/EPA supplementation on the Atlantis Delayed test performance (long term memory and retrieval) in girls, while boys benefitted from supplementation on this measure. On the HVLT, girls receiving DHA/EPA supplementation alone had better recall than placebo or those receiving the combination with iron. 


\section{Discussion}

Infancy, childhood, and adolescence are times of rapid neuronal maturation, synaptogenesis, and gray matter expansion, all of which are associated with brain DHA accumulation $[5,13]$. DHA synthesis from its fatty acid precursors is known to be inefficient, making dietary sources of preformed DHA important [41]. However, DHA is found at high levels in only a very limited number of foods and the typical intake by children worldwide is surprisingly low.

Studies in animals show that omega-3 deficiency causes structural and functional changes in the hippocampus, hypothalamus, and cortex areas of the brain $[18,42,43]$. In animals, reduced levels of brain DHA are associated with problems of spatial and serial learning and memory $[42,44]$ as well as increases in depressive symptoms and aggressive behavior $[45,46]$. In humans, DHA is particularly important during gestation and infancy for early brain and visual development $[47,48]$. There is also growing understanding of the role that $n-3$ LC-PUFA may play in the prevention and treatment of several neuropsychiatric conditions common to children and adults $[49,50]$. Recently, polyunsaturated fatty acids, including DHA, have been studied in children with certain developmental disorders characterized by learning and behavior difficulties. Many of these conditions are associated with abnormal fatty acid status, and whether due to altered fatty acid metabolism or poor intake, some studies show an improvement in symptoms following supplementation with polyunsaturated fatty acids $[22,51,52]$. Healthy children without these neuropsychiatric conditions may also have poor DHA status, due to poor intake. It is therefore plausible that improvements in DHA status could benefit learning and behavior in healthy children as well. The purpose of this review was to determine whether current literature defines a relationship of DHA with learning and behavior in healthy children.

Although there appears to be interest in investigating the effects of DHA and other fatty acids on cognition, learning and behavior in healthy children, the results of our search revealed studies which were very diverse in both research design and focus. For assessment of cognition, the investigators of studies in this review used many and varied age-standardized tests, most of which contained multiple-subtests each measuring a different aspect of cognitive function. There were no apparent consistent results among the studies with regard to treatment effects or DHA biomarker status on specific cognitive tests. In spite of this heterogeneity, however, the studies as a group provide a global view of DHA impact on brain activity and cognition, with over half of the studies reporting significant results favoring a role of DHA or $n$-3 LC-PUFA in at least one area of cognition, learning, or behavior.

Two studies included in this review, demonstrated a benefit of DHA by direct measurement of brain activity using neurophysiological measures of cognitive function during performance of a standardized test. First, the study by McNamara et al. [12] showed the effects of DHA supplementation on brain activity in children as measured by fMRI during performance of a task of sustained attention. Even though outcomes on the standardized task showed no difference as a result of supplementation, probably due to a ceiling effect for the CPT-IP in the children, fMRI data confirmed enhanced activation of the dorsolateral prefrontal cortex (DLPFC) in the DHA-supplemented children. There is a normal age-related increase in DHA content in the prefrontal cortex which occurs during adolescence and young adulthood in healthy well-nourished subjects [13] and the study by McNamara et al. [12] provides a better understanding of the extent to which apparently well-nourished youth may be deficient in DHA and how this deficiency can affect brain activity. Second, a study by Boucher et al. 
used electroencephalographic data to directly assess brain activity in healthy children. In that study, ERP results showed a significant positive association of DHA status with brain activity during performance of a standardized test [27]. While the association with ERP outcomes was stronger for cord blood DHA status than for the child's current plasma DHA, it was still apparent that DHA status in the 10-13 year old children was not optimal and that brain activity was, to some degree, correctable or modifiable through supplementation. There was no effect of DHA status on the outcome of the standardized test.

The findings of McNamara et al. [12] and Boucher et al. [27] are supported by a similar study in an older population. Jackson et al. used near-infrared spectroscopy to assess the relative changes in concentration of oxyhemoglobin and deoxyhemoglobin in the prefrontal cortex of young adults during performance of standardized cognitive tasks [53]. In this study, supplementation with 1- or 2-g DHA-rich fish oil increased concentrations of oxyhemoglobin and total hemoglobin in participants during completion of a standardized test. This pattern of oxygenation is indicative of increased blood flow. As in the studies by Boucher et al. [27] and McNamara et al. [12], there were no consistent changes in performance on the cognitive test in spite of the changes in the hemodynamic response.

Studies such as those by Boucher et al. [27], McNamara et al. [12], and Jackson et al. [52] which demonstrate a DHA relationship with measurable brain activity, but without a concurrent measurable effect on test performance, bring into question the appropriateness or sensitivity of many commonly administered cognitive tests used for assessing DHA adequacy. It is possible that certain tests do not assess the particular cognitive activity affected by DHA. In addition, it is more likely that larger group sizes are required in order achieve the statistical power needed for valid comparisons. From our review, it is interesting that DHA-related improvements in school performance were, however, detectable in some of the studies. In particular, reading performance improved in DHA-supplemented children with poor reading skills in the study by Richardson et al. [36]; and in the study by Dalton et al. [30], spelling performance was maintained in a DHA-supplemented group while the control group experienced a loss of skills. Functions of the brain are often described in modular terms and the type of learning detected in these two studies may involve a coordination of several functions, including memory and attention. Providing adequate DHA may provide small improvements in multiple areas of cognitive function which are ultimately sufficient to affect reading or spelling.

The implication of improving school performance in reading or spelling for struggling students is significant. Reading is described as the major foundational skill for all school-based learning. Students who do not achieve proficiency in reading during the early years of school are known to have difficulty comprehending subject matter in the grades that follow. Educational experts suggest that when students have difficulty learning to read, their love of learning and motivation diminishes [54]. In addition, experts define reading as a critical skill needed not only for academic success, but also for social and economic success [55]. Children with poor reading skills have been shown to experience decreases in self-esteem, self-concept, and further motivation for learning [56] and are more likely to become frustrated, overwhelmed, or disinterested [57]. Given the importance of academic success to children's well-being and ultimate success in life, all educational and environmental factors, including improved nutrition, are worthy of consideration for optimization of learning.

Since changes in normal, healthy children may be difficult to detect, the study design, subject selection, and outcome measure selection are increasingly important. In the study by Richardson et al. [36], 
the authors state that the original trial design required children to rank below the 20th percentile ( 2 years behind actual age) in reading. However, recruitment concerns led the investigators to broaden the inclusion criteria to those scoring below the 33rd percentile (18 months behind actual age) in reading with a pre-planned analysis of children below the 20th and 10th percentile on reading. While no treatment effect was detectable in the whole population, a significant effect on the change from baseline reading scores was detected in children scoring below the 20th percentile and an apparent greater and significant effect was observed for those who scored below the 10th percentile at baseline. Similar findings were reported in a smaller study conducted in children with ADHD which included a subgroup of children who were also behind in their age level in reading and spelling by approximately 2 years. Following 4 months of supplementation with either high EPA or high DHA fish oil, no group differences in behavior or cognition were detected in the group as a whole. However, higher erythrocyte DHA levels were associated with improved word reading, spelling, attention, and oppositional behavior, particularly in the subgroup with reading and spelling difficulties [58].

The doses of DHA supplements used in the studies included in this review varied widely. The $600 \mathrm{mg}$ daily dose of DHA used by Richardson et al. [36] is similar to that used in studies of children with learning disorders; it establishes an effective dose for use in healthy children as well. Whether $600 \mathrm{mg} \mathrm{DHA} /$ day is the optimal dose for healthy children of this age remains to be tested. Future studies are needed to define blood DHA levels, as a surrogate for brain DHA level, which are associated with both the low and improved scores on tests of reading and spelling. Due to differences in study design, methods of measuring and reporting blood DHA, level of DHA supplementation, and compliance, the current literature is still incomplete in this regard. In the study by McNamara et al. [12], mean erythrocyte DHA composition at baseline was $3.3 \%$ of total fatty acids. Following supplementation with $400 \mathrm{mg}$ DHA/day or $1200 \mathrm{mg}$ DHA/day for 8 weeks, erythrocyte DHA composition increased to $7.5 \%$ and $10.3 \%$, respectively. Since these levels were associated with activation of the dorsolateral prefrontal cortex, they could be considered as appropriate goals for future RCTs. Only four other RCTs reported erythrocyte DHA composition as seen in Table 3 [29,31,32,35]. Of these, the studies by Itomura et al. [32] and Hamazaki et al. [31] achieved erythrocyte DHA levels of $7.1 \%$ and $7.5 \%$ total fatty acids, respectively. Baumgartner et al. [29] and Muthayya et al. [35] reported erythrocyte DHA levels of less than $6 \%$ following the supplementation period. The remaining studies either did not report DHA blood status or reported DHA status in a different blood compartment or tissue, making comparisons questionable.

The oils used as placebo in the included studies varied greatly with regard to fatty acid composition. Some, such as medium chain triglycerides provided no additional $n-6$ or $n-3$ PUFA while others provided additional linoleic acid from corn or sunflower oil, ALA from soybean and rapeseed oil, or monounsaturated fatty acids and polyphenols from olive oil. The search for the most appropriate placebo for both human and animal studies has been a topic of debate, with virtually all substitute oils providing fatty acids or other nutrients which on their own can be considered bioactive [59]. For studies specifically designed to increase blood and tissue levels of DHA, oils which supply additional $n-3$ fatty acids in the form of ALA may have minimal effect due to poor conversion of ALA to DHA in humans [41]. However, oils that contribute significant linoleic acid to the diet may reduce DHA accrual in tissues. Studies in animals show decreased incorporation of DHA in retinal tissue in diets high in linoleic acid, and that diets low in linoleic acid support higher brain DHA [60,61]. None of the 
studies in this review reported fatty acid composition of the background diet; therefore it is not clear whether the small amount of oil used in supplementation significantly impacted fatty acid intake of ALA or LA.

In addition to the dose and duration of DHA supplementation, many studies suggest that blood and tissue biomarkers of $n-3$ PUFAs are associated with several common single nucleotide polymorphisms (SNPs) in the genes responsible for encoding the delta 5, and delta 6 desaturases (FADS1 and FADS2), as well as ELOVL2 elongase. Because there is a distinct association of the haplotypes with both $n-3$ and $n-6$ PUFA biomarker status, individuals with variations of these mutations respond differently to $n-3$ supplementation as compared to the larger population. The fatty acid profile associated with SNPs in the FADS1-FADS2 gene cluster includes increased proportions of precursors such as ALA and decreased proportions of desaturation products such as EPA and DHA. However, the biosynthesis of DHA is very limited in the general population and direct consumption of DHA is the primary way to increase DHA status making distinction between the various haplotypes of less significance for this fatty acid. Large observational studies as well as metabolic tracer studies of ALA metabolism in adults indicate that polymorphisms in the FADS1-FADS2 gene cluster do not result in changes in plasma DHA composition under conditions of a controlled diet. Since this review focused on studies which specifically modified dietary DHA, and not its precursors, such genetic variations would be expected to play only a minor role on their outcomes [62-66].

The criteria for inclusion in this review specified that studies report a biomarker of the children's DHA status from the same time-period as the cognitive or behavioral testing. Studies in animals, however, suggest that earlier periods of development may represent a more critical window of time when adequate DHA is particularly essential. Such findings indicate that $n-3$ deficient diets limit DHA accrual during the perinatal period, and if not corrected early, are associated with deficits in neuronal arborization and synaptic formation. Deficient accrual of brain DHA is also associated with deficits in dopamine and serotonin neurotransmission. Development of these two systems of neurotransmission is of particular interest due to their well-known involvement in the control of learning and memory. In a series of studies using a rodent model, Chalon et al. [67] demonstrated that brain DHA decreased in those fed an $n$-3 deficient diet and that this was accompanied by a corresponding decrease in the amount of dopamine in the frontal cortex. Animals fed an $n-3$ repletion diet at birth recovered to normal levels of both brain DHA and dopamine. However, a delay in feeding the $n-3$ repletion diet to the period following weaning resulted in only partial recovery of brain DHA and no recovery of the neurochemical factors. The implication is that early and prolonged insults from a severe $n-3$ deficiency may lead to irreversible damage to specific brain functions. While no critical window of development has been defined in humans, it is possible that differences in early DHA status affect the outcomes of these studies in later childhood [67,68].

\section{Conclusions}

In summary, the studies included in this review generally indicate that improvements in DHA status may initiate brain changes which are observable in activities of learning and behavior. Results of neurophysiologic measures that directly assessed brain activity indicate that brain changes occur in healthy children as the result of DHA supplementation. However, standardized tests of cognition do 
not show consistent changes. The improvement seen in reading and spelling skills following DHA supplementation may represent an accumulation of many subtle changes made over multiple domains that are not readily detectable on other types of tests. These changes may be particularly subtle in healthy children. The reviewed studies conducted in healthy children build on animal data that demonstrate DHA is an essential brain component affecting learning and behavior. While the number of studies is limited, and the design features are diverse, the studies implicate problems in learning and behavior as detrimental effects of DHA deficiency in otherwise healthy children.

\section{Conflict of Interest}

Kuratko, Barrett, Nelson, and Salem, Jr. are employees of DSM Nutritional Products, a producer and seller of polyunsaturated fatty acids, including DHA.

\section{References}

1. Brown, T.T.; Jernigan, T.L. Brain development during the preschool years. Neuropsychol. Rev. 2012, 22, 313-333.

2. Anderson, V.; Fenwick, T.; Manly, T.; Robertson, I. Attentional skills following traumatic brain injury in childhood: A componential analysis. Brain Inj. 1998, 12, 937-949.

3. Barkley, R.A. The executive functions and self-regulation: An evolutionary neuropsychological perspective. Neuropsychol. Rev. 2001, 11, 1-29.

4. Steinberg, L. Psychological control: Style or substance? New Dir. Child Adolesc. Dev. 2005, 2005, 71-78.

5. Carver, J.D.; Benford, V.J.; Han, B.; Cantor, A.B. The relationship between age and the fatty acid composition of cerebral cortex and erythrocytes in human subjects. Brain Res. Bull. 2001, $56,79-85$.

6. Feller, S.E.; Gawrisch, K.; MacKerell, A.D., Jr. Polyunsaturated fatty acids in lipid bilayers: Intrinsic and environmental contributions to their unique physical properties. J. Am. Chem. Soc. 2002, 124, 318-326.

7. Niu, S.L.; Mitchell, D.C.; Lim, S.Y.; Wen, Z.M.; Kim, H.Y.; Salem, N., Jr.; Litman, B.J. Reduced G protein-coupled signaling efficiency in retinal rod outer segments in response to $n-3$ fatty acid deficiency. J. Biol. Chem. 2004, 279, 31098-31104.

8. Champeil-Potokar, G.; Chaumontet, C.; Guesnet, P.; Lavialle, M.; Denis, I. Docosahexaenoic acid (22:6n-3) enrichment of membrane phospholipids increases gap junction coupling capacity in cultured astrocytes. Eur. J. Neurosci. 2006, 24, 3084-3090.

9. Joardar, A.; Sen, A.K.; Das, S. Docosahexaenoic acid facilitates cell maturation and $\beta$-adrenergic transmission in astrocytes. J. Lipid Res. 2006, 47, 571-581.

10. Pifferi, F.; Roux, F.; Langelier, B.; Alessandri, J.M.; Vancassel, S.; Jouin, M.; Lavialle, M.; Guesnet, P. (n-3) Polyunsaturated fatty acid deficiency reduces the expression of both isoforms of the brain glucose transporter GLUT1 in rats. J. Nutr. 2005, 135, 2241-2246.

11. Ximenes da Silva, A.; Lavialle, F.; Gendrot, G.; Guesnet, P.; Alessandri, J.M.; Lavialle, M. Glucose transport and utilization are altered in the brain of rats deficient in $n-3$ polyunsaturated fatty acids. $J$. Neurochem. 2002, 81, 1328-1337. 
12. McNamara, R.K.; Able, J.; Jandacek, R.; Rider, T.; Tso, P.; Eliassen, J.C.; Alfieri, D.; Weber, W.; Jarvis, K.; DelBello, M.P.; et al. Docosahexaenoic acid supplementation increases prefrontal cortex activation during sustained attention in healthy boys: A placebo-controlled, dose-ranging, functional magnetic resonance imaging study. Am. J. Clin. Nutr. 2010, 91, 1060-1067.

13. Giedd, J.N.; Blumenthal, J.; Jeffries, N.O.; Castellanos, F.X.; Liu, H.; Zijdenbos, A.; Paus, T.; Evans, A.C.; Rapoport, J.L. Brain development during childhood and adolescence: A longitudinal MRI study. Nat. Neurosci. 1999, 2, 861-863.

14. Bazan, N.G. Cellular and molecular events mediated by docosahexaenoic acid-derived neuroprotectin D1 signaling in photoreceptor cell survival and brain protection. Prostaglandins Leukot. Essent. Fatty Acids 2009, 81, 205-211.

15. Belayev, L.; Khoutorova, L.; Atkins, K.D.; Bazan, N.G. Robust docosahexaenoic acid-mediated neuroprotection in a rat model of transient, focal cerebral ischemia. Stroke 2009, 40, 3121-3126.

16. Blondeau, N.; Widmann, C.; Lazdunski, M.; Heurteaux, C. Polyunsaturated fatty acids induce ischemic and epileptic tolerance. Neuroscience 2002, 109, 231-241.

17. Ozyurt, B.; Sarsilmaz, M.; Akpolat, N.; Ozyurt, H.; Akyol, O.; Herken, H.; Kus, I. The protective effects of omega-3 fatty acids against MK-801-induced neurotoxicity in prefrontal cortex of rat. Neurochem. Int. 2007, 50, 196-202.

18. Salem, N., Jr.; Litman, B.; Kim, H.Y.; Gawrisch, K. Mechanisms of action of docosahexaenoic acid in the nervous system. Lipids 2001, 36, 945-959.

19. Cohen, J.T.; Bellinger, D.C.; Connor, W.E.; Shaywitz, B.A. A quantitative analysis of prenatal intake of $n-3$ polyunsaturated fatty acids and cognitive development. Am. J. Prev. Med. 2005, 29, 366-374.

20. Yurko-Mauro, K.; McCarthy, D.; Rom, D.; Nelson, E.B.; Ryan, A.S.; Blackwell, A.; Salem, N., Jr.; Stedman, M. Beneficial effects of docosahexaenoic acid on cognition in age-related cognitive decline. Alzheimers Dement. 2010, 6, 456-464.

21. Richardson, A.J.; Montgomery, P. The Oxford-Durham study: A randomized, controlled trial of dietary supplementation with fatty acids in children with developmental coordination disorder. Pediatrics 2005, 115, 1360-1366.

22. Richardson, A.J. Clinical trials of fatty acid treatment in ADHD, dyslexia, dyspraxia and the autistic spectrum. Prostaglandins Leukot. Essent. Fatty Acids 2004, 70, 383-390.

23. Stevens, L.J.; Zentall, S.S.; Deck, J.L.; Abate, M.L.; Watkins, B.A.; Lipp, S.R.; Burgess, J.R. Essential fatty acid metabolism in boys with attention-deficit hyperactivity disorder. Am. J. Clin. Nutr. 1995, 62, 761-768.

24. Mitchell, E.A.; Aman, M.G.; Turbott, S.H.; Manku, M. Clinical characteristics and serum essential fatty acid levels in hyperactive children. Clin. Pediatr. (Phila.) 1987, 26, 406-411.

25. Richardson, A.J.; Ross, M.A. Fatty acid metabolism in neurodevelopmental disorder: A new perspective on associations between attention-deficit/hyperactivity disorder, dyslexia, dyspraxia and the autistic spectrum. Prostaglandins Leukot. Essen. Fatty Acids 2000, 63, 1-9.

26. Bakker, E.C.; Ghys, A.J.; Kester, A.D.; Vles, J.S.; Dubas, J.S.; Blanco, C.E.; Hornstra, G. Long-chain polyunsaturated fatty acids at birth and cognitive function at 7 years of age. Eur. J. Clin. Nutr. 2003, 57, 89-95. 
27. Boucher, O.; Burden, M.J.; Muckle, G.; Saint-Amour, D.; Ayotte, P.; Dewailly, E.; Nelson, C.A.; Jacobson, S.W.; Jacobson, J.L. Neurophysiologic and neurobehavioral evidence of beneficial effects of prenatal omega-3 fatty acid intake on memory function at school age. Am. J. Clin. Nutr. 2011, 93, 1025-1037.

28. Kirby, A.; Woodward, A.; Jackson, S.; Wang, Y.; Crawford, M.A. Childrens' learning and behaviour and the association with cheek cell polyunsaturated fatty acid levels. Res. Dev. Disabil. 2010, 31, 731-742.

29. Baumgartner, J.; Smuts, C.M.; Malan, L.; Kvalsvig, J.; van Stuijvenberg, M.E.; Hurrell, R.F.; Zimmermann, M.B. Effects of iron and n-3 fatty acid supplementation, alone and in combination, on cognition in school children: A randomized, double-blind, placebo-controlled intervention in South Africa. Am. J. Clin. Nutr. 2012, 96, 1327-1338.

30. Dalton, A.; Wolmarans, P.; Witthuhn, R.C.; van Stuijvenberg, M.E.; Swanevelder, S.A.; Smuts, C.M. A randomised control trial in schoolchildren showed improvement in cognitive function after consuming a bread spread, containing fish flour from a marine source. Prostaglandins Leukot. Essent. Fatty Acids 2009, 80, 143-149.

31. Hamazaki, K.; Syafruddin, D.; Tunru, I.S.; Azwir, M.F.; Asih, P.B.; Sawazaki, S.; Hamazaki, T. The effects of docosahexaenoic acid-rich fish oil on behavior, school attendance rate and malaria infection in school children-A double-blind, randomized, placebo-controlled trial in Lampung, Indonesia. Asia Pac. J. Clin. Nutr. 2008, 17, 258-263.

32. Itomura, M.; Hamazaki, K.; Sawazaki, S.; Kobayashi, M.; Terasawa, K.; Watanabe, S.; Hamazaki, T. The effect of fish oil on physical aggression in schoolchildren-A randomized, double-blind, placebo-controlled trial. J. Nutr. Biochem. 2005, 16, 163-171.

33. Kennedy, D.O.; Jackson, P.A.; Elliott, J.M.; Scholey, A.B.; Robertson, B.C.; Greer, J.; Tiplady, B.; Buchanan, T.; Haskell, C.F. Cognitive and mood effects of 8 weeks' supplementation with $400 \mathrm{mg}$ or $1000 \mathrm{mg}$ of the omega-3 essential fatty acid docosahexaenoic acid (DHA) in healthy children aged 10-12 years. Nutr. Neurosci. 2009, 12, 48-56.

34. Kirby, A.; Woodward, A.; Jackson, S.; Wang, Y.; Crawford, M.A. A double-blind, placebo-controlled study investigating the effects of omega-3 supplementation in children aged 8-10 years from a mainstream school population. Res. Dev. Disabil. 2010, 31, 718-730.

35. Muthayya, S.; Eilander, A.; Transler, C.; Thomas, T.; van der Knaap, H.C.; Srinivasan, K.; van Klinken, B.J.; Osendarp, S.J.; Kurpad, A.V. Effect of fortification with multiple micronutrients and $n-3$ fatty acids on growth and cognitive performance in Indian schoolchildren: The CHAMPION (Children's Health and Mental Performance Influenced by Optimal Nutrition) Study. Am. J. Clin. Nutr. 2009, 89, 1766-1775.

36. Richardson, A.J.; Burton, J.R.; Sewell, R.P.; Spreckelsen, T.F.; Montgomery, P. Docosahexaenoic acid for reading, cognition and behavior in children aged 7-9 years: A randomized, controlled trial (the DOLAB Study). PLoS One 2012, 7, e43909.

37. Ryan, A.S.; Nelson, E.B. Assessing the effect of docosahexaenoic acid on cognitive functions in healthy, preschool children: A randomized, placebo-controlled, double-blind study. Clin. Pediatr. (Phila.) 2008, 47, 355-362. 
38. Sinn, N.; Cooper, P.; O’Dea, K. Fish oil supplementation, learning and behaviour in Indigenous Australian children from a remote community school: A pilot feasibility study. Aust. N. Z. J. Public Health 2011, 35, 493-494.

39. Osendarp, S.J.; Baghurst, K.I.; Bryan, J.; Calvaresi, E.; Hughes, D.; Hussaini, M.; Karyadi, S.J.; van Klinken, B.J.; van der Knaap, H.C.; Lukito, W.; et al. Effect of a 12-mo micronutrient intervention on learning and memory in well-nourished and marginally nourished school-aged children: 2 Parallel, randomized, placebo-controlled studies in Australia and Indonesia. Am. J. Clin. Nutr. 2007, 86, 1082-1093.

40. Bryan, J.; Osendarp, S.; Hughes, D.; Calvaresi, E.; Baghurst, K.; van Klinken, J.W. Nutrients for cognitive development in school-aged children. Nutr. Rev. 2004, 62, 295-306.

41. Brenna, J.T.; Salem, N., Jr.; Sinclair, A.J.; Cunnane, S.C. $\alpha$-Linolenic acid supplementation and conversion to $n$-3 long-chain polyunsaturated fatty acids in humans. Prostaglandins Leukot. Essent. Fatty Acids 2009, 80, 85-91.

42. Moriguchi, T.; Salem, N., Jr. Recovery of brain docosahexaenoate leads to recovery of spatial task performance. J. Neurochem. 2003, 87, 297-309.

43. Lim, S.Y.; Hoshiba, J.; Salem, N., Jr. An extraordinary degree of structural specificity is required in neural phospholipids for optimal brain function: $n-6$ Docosapentaenoic acid substitution for docosahexaenoic acid leads to a loss in spatial task performance. J. Neurochem. 2005, 95, 848-857.

44. Fedorova, I.; Hussein, N.; Baumann, M.H.; di Martino, C.; Salem, N., Jr. An n-3 fatty acid deficiency impairs rat spatial learning in the Barnes maze. Behav. Neurosci. 2009, 123, 196-205.

45. DeMar, J.C., Jr.; Ma, K.; Bell, J.M.; Igarashi, M.; Greenstein, D.; Rapoport, S.I. One generation of $n-3$ polyunsaturated fatty acid deprivation increases depression and aggression test scores in rats. J. Lipid Res. 2006, 47, 172-180.

46. Fedorova, I.; Salem, N., Jr. Omega-3 fatty acids and rodent behavior. Prostaglandins Leukot. Essent. Fatty Acids 2006, 75, 271-289.

47. Jensen, C.L.; Voigt, R.G.; Prager, T.C.; Zou, Y.L.; Fraley, J.K.; Rozelle, J.C.; Turcich, M.R.; Llorente, A.M.; Anderson, R.E.; Heird, W.C. Effects of maternal docosahexaenoic acid intake on visual function and neurodevelopment in breastfed term infants. Am. J. Clin. Nutr. 2005, 82, $125-132$.

48. Birch, E.E.; Garfield, S.; Castaneda, Y.; Hughbanks-Wheaton, D.; Uauy, R.; Hoffman, D. Visual acuity and cognitive outcomes at 4 years of age in a double-blind, randomized trial of long-chain polyunsaturated fatty acid-supplemented infant formula. Early Hum. Dev. 2007, 83, 279-284.

49. Bloch, M.H.; Hannestad, J. Omega-3 fatty acids for the treatment of depression: Systematic review and meta-analysis. Mol. Psychiatry 2012, 17, 1272-1282.

50. Freeman, M.P.; Hibbeln, J.R.; Wisner, K.L.; Davis, J.M.; Mischoulon, D.; Peet, M.; Keck, P.E., Jr.; Marangell, L.B.; Richardson, A.J.; Lake, J.; et al. Omega-3 fatty acids: Evidence basis for treatment and future research in psychiatry. J. Clin. Psychiatry 2006, 67, 1954-1967.

51. Bloch, M.H.; Qawasmi, A. Omega-3 fatty acid supplementation for the treatment of children with attention-deficit/hyperactivity disorder symptomatology: Systematic review and meta-analysis. J. Am. Acad. Child Adolesc. Psychiatry 2011, 50, 991-1000. 
52. Milte, C.M.; Sinn, N.; Buckley, J.D.; Coates, A.M.; Young, R.M.; Howe, P.R. Polyunsaturated fatty acids, cognition and literacy in children with ADHD with and without learning difficulties. J. Child Health Care 2011, 15, 299-311.

53. Jackson, P.A.; Reay, J.L.; Scholey, A.B.; Kennedy, D.O. Docosahexaenoic acid-rich fish oil modulates the cerebral hemodynamic response to cognitive tasks in healthy young adults. Biol. Psychol. 2012, 89, 183-190.

54. Stanovich, K. Matthew effects in reading: Some consequences of individual differences in the acquisition of literacy. Read. Res. Q. 1986, 22, 360-406.

55. Snow, C.; Burns, S.; Griffin, P. Preventing Reading Difficulties in Young Children; National Academies Press: Washington, DC, USA, 1998.

56. Armbruster, B.; Lehr, F.; Osborn, J. Putting Reading First. In The Research Building Blocks for Teaching Children to Read: Kindergarten through Grade 3, 3rd ed.; Adler, R., Ed.; Diane Publishing Co.: Darby, PA, USA, 2010.

57. Morrison, F.; Cosden, M. Risk, resilience, and adjustment of individuals with learning disabilities. Learn. Disabil. Q. 1997, 20, 43-60.

58. Milte, C.M.; Parletta, N.; Buckley, J.D.; Coates, A.M.; Young, R.M.; Howe, P.R. Eicosapentaenoic and docosahexaenoic acids, cognition, and behavior in children with attentiondeficit/hyperactivity disorder: A randomized controlled trial. Nutrition 2012, 28, 670-677.

59. Dyall, S.C. Methodological issues and inconsistencies in the field of omega-3 fatty acids research. Prostaglandins Leukot. Essent. Fatty Acids 2011, 85, 281-285.

60. Weisinger, H.S.; Vingrys, A.J.; Sinclair, A.J. The effect of docosahexaenoic acid on the electroretinogram of the guinea pig. Lipids 1996, 31, 65-70.

61. Novak, E.M.; Dyer, R.A.; Innis, S.M. High dietary omega-6 fatty acids contribute to reduced docosahexaenoic acid in the developing brain and inhibit secondary neurite growth. Brain Res. 2008, 1237, 136-145.

62. Gillingham, L.G.; Harding, S.V.; Rideout, T.C.; Yurkova, N.; Cunnane, S.C.; Eck, P.K.; Jones, P.J. Dietary oils and FADS1-FADS2 genetic variants modulate [13C] alpha-linolenic acid metabolism and plasma fatty acid composition. Am. J. Clin. Nutr. 2013, 97, 195-207.

63. Malerba, G.; Schaeffer, L.; Xumerle, L.; Klopp, N.; Trabetti, E.; Biscuola, M.; Cavallari, U.; Galavotti, R.; Martinelli, N.; Guarini, P.; et al. SNPs of the FADS gene cluster are associated with polyunsaturated fatty acids in a cohort of patients with cardiovascular disease. Lipids 2008, 43, 289-299.

64. Schaeffer, L.; Gohlke, H.; Muller, M.; Heid, I.M.; Palmer, L.J.; Kompauer, I.; Demmelmair, H.; Illig, T.; Koletzko, B.; Heinrich, J. Common genetic variants of the FADS1 FADS2 gene cluster and their reconstructed haplotypes are associated with the fatty acid composition in phospholipids. Hum. Mol. Genet. 2006, 15, 1745-1756. 
65. Rzehak, P.; Heinrich, J.; Klopp, N.; Schaeffer, L.; Hoff, S.; Wolfram, G.; Illig, T.; Linseisen, J. Evidence for an association between genetic variants of the fatty acid desaturase 1 fatty acid desaturase 2 (FADS1 FADS2) gene cluster and the fatty acid composition of erythrocyte membranes. Br. J. Nutr. 2009, 101, 20-26.

66. Tanaka, T.; Shen, J.; Abecasis, G.R.; Kisialiou, A.; Ordovas, J.M.; Guralnik, J.M.; Singleton, A.; Bandinelli, S.; Cherubini, A.; Arnett, D.; et al. Genome-wide association study of plasma polyunsaturated fatty acids in the InCHIANTI Study. PLoS Genet. 2009, 5, e1000338.

67. Chalon, S. Omega-3 fatty acids and monoamine neurotransmission. Prostaglandins Leukot. Essent. Fatty Acids 2006, 75, 259-269.

68. Kodas, E.; Vancassel, S.; Lejeune, B.; Guilloteau, D.; Chalon, S. Reversibility of $n-3$ fatty acid deficiency-induced changes in dopaminergic neurotransmission in rats: Critical role of developmental stage. J. Lipid Res. 2002, 43, 1209-1219.

(C) 2013 by the authors; licensee MDPI, Basel, Switzerland. This article is an open access article distributed under the terms and conditions of the Creative Commons Attribution license (http://creativecommons.org/licenses/by/3.0/). 